\title{
Characterization of Functional Single Jersey Knitted Fabrics Using Non- Conventional Yarns for Sportswear
}

\author{
Jefferson M Souza ${ }^{1}$, Sandra Sampaio ${ }^{1}$, Welter C Silva ${ }^{22}$, \\ Sidney G de Lima ${ }^{2}$, Andrea Zille ${ }^{1}$ and Raul Fangueiro ${ }^{1}$
}

\begin{abstract}
Eight functional single jersey plain knitted fabrics have been developed in order to assess a quantitative analysis of various comfort related properties in terms of thermal control, air and water vapour permeability, wickability, coefficient of kinetic friction and antimicrobial efficiency using eight different commercially available functional yarns: Polyester $\mathrm{Craque}^{\circledR}$ and viscose Craque $^{\circledR}$ conventional yarns as controls; Finecool ${ }^{\circledR}$ and Coolmax ${ }^{\circledR}$ polyester yarns for moisture management and quick dry; Holofiber ${ }^{\circledR}$ polyester yarns containing an optical responsive material that the producer claims to improve body oxygenation; Airclo ${ }^{\circledR}$ polyester hollow yarns for efficient control of body temperature and finally polyester Trevira ${ }^{\circledR}$ and viscose Seacell ${ }^{\circledast}$ for antimicrobial activity. According to the results, Coolmax ${ }^{\circledR}$ for moisture management, Airclo $^{\circledR}$ for thermal control and Seacell ${ }^{\circledR}$ for antimicrobial activity present the best performances as technical textiles for sportwear in the respective specific functional property.
\end{abstract}

Corresponding author:

Andrea Zille, Centro de Ciência e Tecnologia Têxtil (2C2T), Universidade do Minho, Campus de Azurém, 4800-058

Guimarães, Portugal.

E-mail: azille@2c2t.uminho.pt; andrea.zille@gmail.com

\footnotetext{
${ }^{1}$ Centro de Ciência e Tecnologia Têxtil (2C2T), Universidade do Minho, Portugal

2 Departamento de Quimica, Universidade Federal do Piauí, Brazil
} 


\section{Introduction}

Sportwears are an important arena for the development of new product with functional characteristics. Technical textiles for sportwear must offer comfort functions as well as adequate protection. Comfort is one of the most important aspects of clothing. It strongly affects the choices people make when buying clothes, and a considerable amount of research has been produced on this subject. However, few information is available about the specific role of fabric materials and wearing conditions on human comfort responses. ${ }^{1}$

The most important functions expected in high performing sportswear fabrics are: i) Heat transport properties to maintain body temperature; ii) Moisture transport performance by changing the cross sections of the fibre to keep the body dry; iii) Anti-static performances to dissipate electrical charge; iv) Antimicrobial performances to keep low the bacteria proliferation on the skin; v) Ultraviolet protection to block dangerous UV-A and UV-B rays. ${ }^{2}$

It is widely known that heat transfer, moisture and air through a garment are important factors for clothing comfort to keep the user dry and comfortable and control the odour. ${ }^{3}$ The thermophysiological comfort experienced through wearing clothing is determined by the sensation of warmth or coolness at contact with the fabric as well as by the loss of water vapour through the clothing, which regulates the heat balance of the body. New standards for comfort are being achieved with lightweight, stretchy materials that wick and feel soft next to the skin such as the Dri-Fit $^{\circledR}$ and Coolmax ${ }^{\circledR}$ performance fabrics. ${ }^{4}$

Also the growth of microbes on textiles during use and storage negatively affects the wearer as well as the textile itself ${ }^{5}$. Microbes may cause discoloration, staining, and changing the mechanical properties. Moreover, they can lead to odour formation, while pathogen microorganisms may adversely affect human health, causing athlete's foot, bedsores, allergies, or cross-infections in hospitals. ${ }^{6}$ The detrimental effects can be controlled by durable antimicrobial finishing of the textile using broad-spectrum biocides or by incorporating the biocide into synthetic fibres during extrusion. ${ }^{7,8}$

Nevertheless, it is not possible to achieve all required properties for sportswear using a single fibre. The behaviour of the fabric will depend by the fibre type, the weave construction, the chemistry, weight and thickness of the material and the presence of chemical treatments.

A wide range of woven, knitted and nonwoven fabrics are commercially available for sportswear with different structure and surface properties. However, for sportswear knitted fabrics are preferred because of their unique transmission characteristics such as water vapour permeability, air permeability, thermal conductivity and moisture management property. ${ }^{9}$ Moreover, they provide outstanding comfort qualities, lightweight warmth, wrinkle resistance 
and ease of care and have greater elasticity and stretchability compared to woven fabrics. ${ }^{10}$ Despite cotton's provides a good combination of softness and comfort, it is not recommended for use in active sportswear because of its tendency to absorb and retain moisture and causing discomfort. Synthetic fabrics are generally considered a better alternative for sportswear as they are able to provide a good heat and moisture management allowing body temperature regulation, improved muscle performance and delayed exhaustion. ${ }^{2}$ Nowadays, polyester is the most widely and popularly used fibre because of its favourable characteristics, namely outstanding dimensional stability, high strength, easy care, wrinkle-free, excellent resistance to dirt, alkalis, decay, mould and most common organic solvents. ${ }^{11}$

Increasingly aware of the comfort properties of the fabrics and the need of durable antimicrobial properties, eight different fabrics of single jersey plain structure were knitted using eight different commercially available yarns with different properties. The thermal and moisture management properties, the wicking behaviour, the coefficient of kinetic friction and the drying rate of the knitted fabrics incorporating yarns with different thermoregulating effect were investigated. Moreover, the antimicrobial fabrics were washed up to 15 times and the antimicrobial efficiency was evaluated against several microorganisms. The thermal properties, air permeability, water vapour permeability and the coefficient of kinetic friction of the antimicrobial samples were also measured and compared to the conventional fibre based knitted fabrics. 


\section{Materials and Methods}

\subsection{Materials}

Eight different single jersey knitted fabrics were produced using an 8-feed circular knitting seamless machine MERZ MBS (Germany): 28 E gauge, 13 inches cylinder diameter, 1152 needles, 3,5 and 7 yarn guides (this is the number of yarn guides contained in each feeding head. Each of the yarn guides has a passage for one yarn to be fed to the needles of the machine) and $80 \mathrm{rpm}$ velocity. The yarn input tension and the loop length setting were kept constant for all the samples at $2 \mathrm{cN}$ and 100, respectively. Characteristics of the used yarns and produced knitted fabrics are presented in Table 1. Polyester Craque ${ }^{\circledR}$ and viscose Craque ${ }^{\circledR}$ are conventional fibres and were used as controls. Finecool ${ }^{\circledR}$ and Coolmax ${ }^{\circledR}$ are kind of functional fibres designed for moisture management and quick dry. Holofiber ${ }^{\circledast}$ is a fibre containing an optical responsive material that as claimed by the producer is able to alter certain wavelengths into energy to better oxygenate the body. Airclo ${ }^{\circledR}$ fibres are hollow-core filament that entraps insulating air for supposedly provide an efficient control of body temperature. Polyester Trevira $^{\circledR}$ and Viscose Seacell ${ }^{\circledR}$ are fibres integrating antimicrobial silver in their structure. Thickness was measured under a pressure of $100 \mathrm{~Pa}$ (standard pressure for knitted fabrics). After Knitting a single standard washing was performed before characterization according to the stipulated in standard ISO 105 C06, method A1S, at temperature of 40 ㅇ. .

Table 1. Characteristics of the produced knitted fabrics (Data represent mean values $\pm S D$ $(n=3)$.

\begin{tabular}{lccccccc}
\hline Sample & $\begin{array}{c}\text { Yarn } \\
\text { linear } \\
\text { density } \\
\text { (dtex) }\end{array}$ & Courses/cm & Wales/cm & $\begin{array}{c}\text { Areal } \\
\text { Density } \\
\left(\mathbf{g} / \mathbf{m}^{2}\right)\end{array}$ & $\begin{array}{c}\text { Thickness } \\
(\mathbf{m m})\end{array}$ & $\begin{array}{c}\text { Loop } \\
\text { length } \\
(\mathbf{m m})\end{array}$ & $\begin{array}{c}\text { Cover } \\
\text { Factor } \\
\text { (K) }\end{array}$ \\
\hline $\begin{array}{l}\text { Polyester } \\
\text { Craque }\end{array}$ & 2.4 & $14 \pm 1$ & $22 \pm 1$ & $168.7 \pm 2.5$ & $0.7 \pm 0.05$ & $2.7 \pm 0.05$ & 16.9 \\
$\begin{array}{l}\text { Polyester } \\
\text { Finecool }\end{array}$ & 2.4 & $14 \pm 1$ & $21 \pm 1$ & $158.9 \pm 2.1$ & $0.8 \pm 0.05$ & $2.7 \pm 0.05$ & 16.6 \\
$\begin{array}{l}\text { Polyester } \\
\text { Coolmax }\end{array}$ & 2.4 & $15 \pm 1$ & $20 \pm 1$ & $163.5 \pm 2.1$ & $0.7 \pm 0.05$ & $2.8 \pm 0.05$ & 16.4 \\
$\begin{array}{l}\text { Polyester } \\
\text { Holofiber }\end{array}$ & $0.7(\times 3)$ & $16 \pm 1$ & $21 \pm 1$ & $189.0 \pm 3.6$ & $0.7 \pm 0.05$ & $2.9 \pm 0.05$ & 15.3 \\
Polyester & 2.4 & $14 \pm 1$ & $22 \pm 1$ & $158.1 \pm 2.4$ & $0.9 \pm 0.05$ & $2.8 \pm 0.05$ & 15.7
\end{tabular}


Airclo $^{\circledR}$

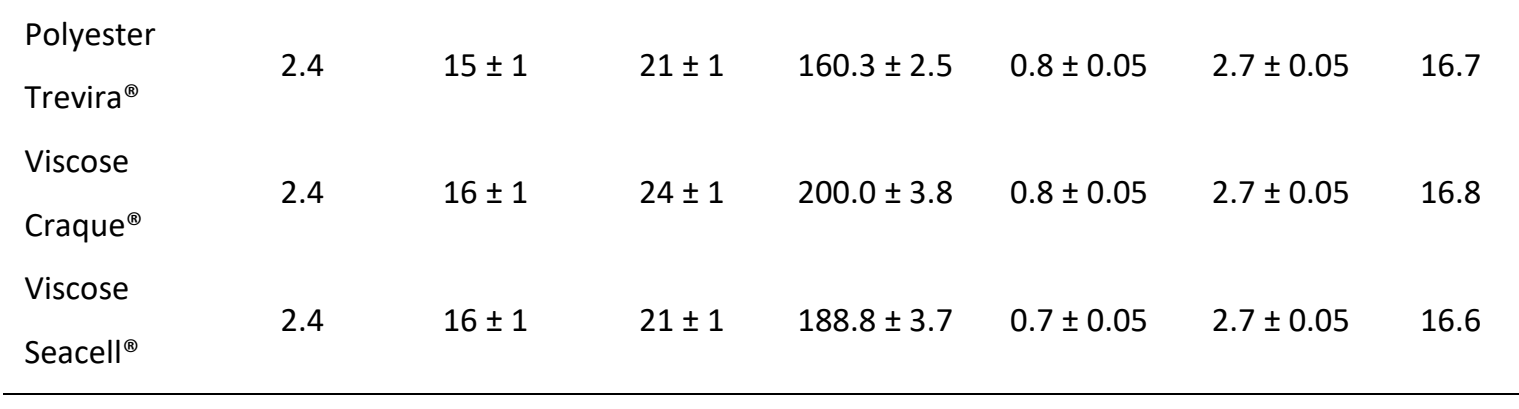

\subsection{Optical microscopy}

For morphology analysis all yarn samples were immobilised on a resin prior to transversal cut. The cross section was recorded using a reflection optical microscope Olympus BH (Japan) coupled to a JVC TK1280E (Japan) camera and Micron Measurement video recorder capture software Leica Quantimet 500 (Germany). The samples were observed separately for a period of 5 min using a magnification of $40 \times 65$. The images were saved in grey scale (16 bit) and zoomed to select a representative fibre. Some backgrounds were manipulated in order to remove undesired image artefacts. The images were also optimized in term of contrast and brightness using the function "auto level" by the program Graphic Converter 9.7.5 of Lemke Software GmbH, Germany.

\subsection{Thermal properties}

Thermal properties (thermal conductivity, thermal resistance, thermal absorptivity, thermal diffusivity and heat flux) of Knitted fabrics were measured on Alambeta instrument by Sensora (Czech Republic) and tests performed according to standard ISO EN 31092-1994. The Alambeta simulates the dry human skin and is based on the principle of measurement of heat power passing through the test fabric due to the difference in temperature between the bottom measuring plate $\left(22^{\circ} \mathrm{C}\right)$ and the top measuring head $\left(32^{\circ} \mathrm{C}\right)$. The hot plate comes in contact with the fabric sample at a pressure of $200 \mathrm{~Pa}$. As soon as the plate touches the fabric, the amount of heat power transferred from the hot surface to the cold surface through the fabric is detected and processed to calculate the thermal parameters of fabric. Average of 10 readings was taken for each sample and the data are reported as mean \pm standard deviation.

\subsection{Air permeability}

Air permeability tests of the knitted fabrics investigated were done according to NP EN standard ISO 9237:1997 using a head area of $20 \mathrm{~cm}^{2}$ and differential pressure of $100 \mathrm{~Pa}$. Air permeability is the rate of air passing perpendicularly through a known area under a 
prescribed air pressure differential between the two surfaces of a material. Air permeability was measured on a FX 3300 air permeability tester by Textest AG, Switzerland at the standard condition of $65 \% \mathrm{RH}$ and $20^{\circ} \mathrm{C}$. Average of 10 readings was taken and the data are reported as mean \pm standard deviation.

\subsection{Water vapour permeability}

The water vapour permeability was determined on SDL Shirley Water Vapour Permeability Tester M-261, according to standard BS 7209-1990. As per the British standard the test specimen is sealed over the open mouth of a test dish which contains water and the assembly is placed in a controlled atmosphere of $20^{\circ} \mathrm{C}$ and $65 \%$ relative humidity. Following a period of 1 hour to establish equilibrium of water vapour pressure gradient across the sample, successive weighing of the assembled dish were made and the rate of water vapour permeation through the specimen is determined. All the experiments were replicated 5 times, and the data are reported as mean \pm standard deviation.

\subsection{Surface friction}

The surface friction of the knitted fabrics was measured by a FRICTORQ device (University of Minho, Portugal) at the standard condition of $65 \% \mathrm{RH}$ and $20^{\circ} \mathrm{C}$. Frictorq is based on a rotary movement and measurement of the friction reaction torque. The principle is based on an annular shaped upper body rubbing against a flat lower fabric. The fabric sample is forced to rotate around a vertical axis at a constant angular velocity. The coefficient of kinetic friction is then proportional to the torque measured by means of a high precision torque sensor. All the experiments were replicated 5 times, and the data are reported as mean \pm standard deviation.

\subsection{Vertical wicking tests}

Vertical wicking tests were performed at $20 \pm 2{ }^{\circ} \mathrm{C}$ and $65 \pm 2 \%$ of relative humidity. Specimens of $20 \mathrm{~cm} \times 2.5 \mathrm{~cm}$ cut along the wale-wise and course-wise directions were suspended vertically with its bottom end dipped in a reservoir of distilled water. The bottom end of each specimen was clamped with a $1.2 \mathrm{~g}$ clip to ensure that the bottom end was immersed vertically at a depth of $30 \mathrm{~mm}$ into the water. The wicking heights were measured every minute for 10 $\min$. All the experiments were replicated 5 times, and the data are reported as mean \pm standard deviation.

\subsection{Horizontal wicking tests}


Horizontal wicking tests were performed at $20 \pm 2{ }^{\circ} \mathrm{C}$ and $65 \pm 2 \%$ of relative humidity. Specimens of $20 \mathrm{~cm} \times 20 \mathrm{~cm}$ were placed horizontally between two glass plates with a tiny drop of water placed on the fabric. The water absorption takes place by wicking and wetting through the pores. The water is supplied continuously from a reservoir with $75 \mathrm{~g}$ of water by siphoning to the bottom of the specimen. The reservoir is kept on an electronic balance, which enables the recording of the water mass absorbed by the fabric. The wicking were measured every minute for $5 \mathrm{~min}$ and expressed as the percentage of absorbed water weight in respect to the water in the reservoir. All the experiments were replicated five times, and the data are reported as mean \pm standard deviation.

\subsection{Drying capability}

Drying capability was evaluated by the drying rate of the fabric. The specimen was cut as a 20 $\mathrm{cm} \times 20 \mathrm{~cm}$ square and placed on a balance. In order to determine the drying rate (evaporating curve), the fabrics were weighted in the dry state $\left(\mathrm{W}_{\mathrm{f}}\right)$ and with an initial water weight equal to $30 \%$ of the dry sample weight $\left(\mathrm{W}_{0}\right)$. The change in weight $\left(\mathrm{W}_{\mathrm{i}}\right)$ was measured every minute for the first 5 minutes and then every 5 minutes up to 30 minutes. The remaining water ratio (\%) was calculated using the equation: $\operatorname{RWR}(\%)=\left(W_{i}-W_{f}\right) /\left(W_{0}-W_{f}\right) * 100$. The remaining water ratios were used to express the drying ability of the fabrics. In order to assess the dry capability of the fabric at room temperature and at the human internal body temperature the experiments were performed at $20^{\circ} \mathrm{C}$ and $37^{\circ} \mathrm{C}$. All the experiments were replicated 5 times, and the data are reported as mean \pm standard deviation.

\subsection{Antimicrobial assay}

The microbial population (total colony forming units) of controlled (conventional yarn fabrics) and antimicrobial fabric samples were determined quantitatively using AATCC-100 test method. Sample size taken for determination of bacterial population was $5 \mathrm{~cm} \times 5 \mathrm{~cm}$. $500 \mathrm{ml}$ conical flasks containing $50 \mathrm{ml}$ of nutrients broth were prepared and sterilized at $121^{\circ} \mathrm{C}$ for 15 minutes. It was then allowed to cool. The fabric samples were subsequently transferred aseptically into conical flasks. These were incubated at $37{ }^{\circ} \mathrm{C}$ for 24 hours in shaker at $121 \mathrm{rpm}$. To allow bacterial samples count, serial dilution (10:1, 10:2 and 10:3) was carried out and bacterial reduction was calculated. The durability of the antimicrobial fabrics against repeated launderings (5, 10 and 15 washing cycles) was evaluated by washing all samples in the 'Launder-o-meter' by using standard ISO: 6330-1984E. The antimicrobial fabric samples were then subjected to bacterial test and the bacterial growth was again analysed. All antibacterial data represent mean values $\pm S D(n=3)$. 



\section{Results and Discussion}

\subsection{Morphological analysis}

Figure 1 shows the optical microscopic images of the cross sections of the fibers used to produce the knitted fabrics. Figure 1a shows a conventional polyester fibre with well-defined circular cross sections. Finecool ${ }^{\circledR}$ polyester is a rhomboid cross section (Figure 1b) functional microfiber with moisture management abilities and is the smallest fibre used in this work. Polyester Coolmax ${ }^{\circledast}$ yarns are microfibers made of specially spun and moulded polyester able to evaporate moisture quickly. Coolmax ${ }^{\circledR}$ fibres are not round (Figure 1c), but are slightly oblong in cross-section with grooves running lengthwise along the threads. This particular shape generates a much higher fibre surface area than circular cross-section fibres, which increases capillary action that wicks moisture through the core and out to a wider area on the surface of the fabric increasing evaporation. They are manufactured in either a tetrachannel (the used in this work) or hexachannel style. The series of closely spaced channels increase the specific surface-area of the fibres and improve capillary force of the hydrophobic polyester fibre bundle and enhance the wicking of polyester fabric. ${ }^{12}$ The Holofiber ${ }^{\circledast}$ polyester is a responsive yarn that interacts with the human body to increase oxygen levels, resulting in increased strength, energy and accelerated muscle recovery. They display a small nucleus with a circular cross section (Figure 1d). Holofiber ${ }^{\circledR}$ contains an optical responsive material that scatter and reflect visible and near infrared light. The energy is then supposedly transmitted to the body to better oxygenate the body's cells. It is conceivable that some interaction of the Holofiber ${ }^{\circledast}$ particles with light increases reflection or transmission of light in the visible or near infrared portion of the spectrum into the skin, leading to vasodilation of the microcirculation and enhanced perfusion of tissues. Some evidence suggests that short periods of illuminating skin, tissue, and cells with visible or infrared light has positive effects on pain, injury recovery, and wound healing. ${ }^{13}$ Airclo ${ }^{\circledR}$ yarn is a hollow (Figure 1e), lightweight fibre with $24 \%$ hollow rate that is manufactured from a high-quality polyester with an advanced spinning technology. Hollow-core filament entraps insulating air for efficient body temperature condition. It also has an excellent resilience and the ability to retain heat as well as excellent bulkiness and soft touchiness. Among the fibres used in this work Airclo@ yarns display the biggest diameter. Hollow fibre has many special properties in comparison with cylindrical fibre since the internal diameter will affect the thermal sensitive heat transfer of the fabric according to the environment and body temperature. ${ }^{14}$ The antimicrobial polyester fibres produced by Trevira ${ }^{\circledR}$ have silver particles incorporated into the fibres before extrusion. It has a well-defined circular cross-section, which does not differ so much in shape and in size from its corresponding 
conventional yarn (Figure 1f). During use, silver diffuses onto the surface of the fibre and forms silver ions in the presence of moisture. The rate of silver release can be influenced by the chemistry and physical characteristics of the fibre and the amount of silver in the fibre. ${ }^{15}$ The SeaCell ${ }^{\circledR}$ active viscose yarn as it can be seen from Figure $1 \mathrm{~g}$ has an oval shape cross-section which contrasts with the typical crack shape cross-section of the conventional viscose yarns (Figure 1h). SeaCell ${ }^{\circledR}$ active is based on viscose with incorporated seaweed and silver nanoparticles. These additional materials could define the final shape of the fibre cross section. ${ }^{16}$ The natural, cellulose- and seaweed-based SeaCell ${ }^{\circledR}$ fibres in addition to serve as a functional carrier for the antifungal and antibacterial silver, contain the minerals calcium, magnesium, and sodium, which are known to play a key role in skin homeostasis. ${ }^{17}$
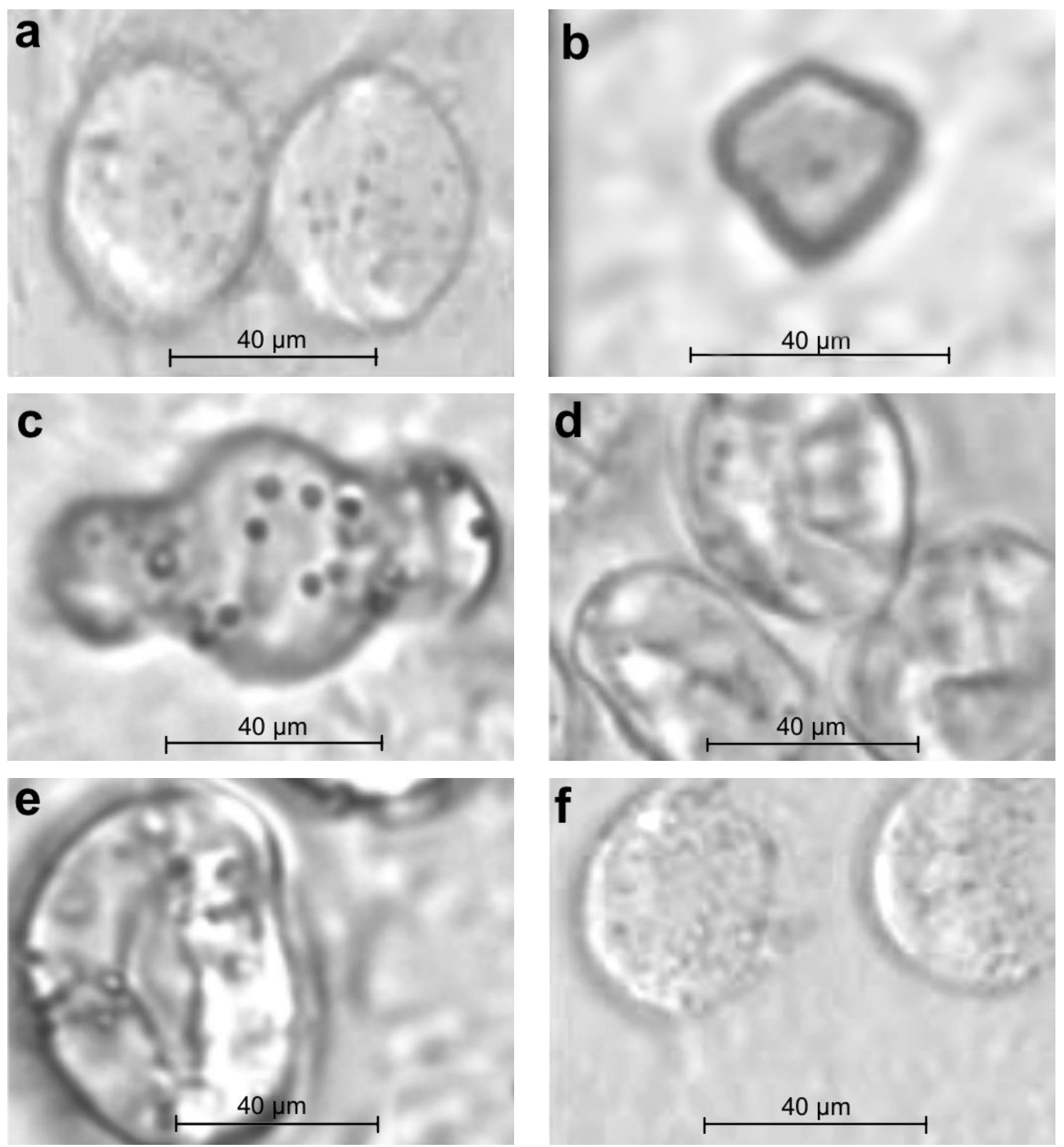

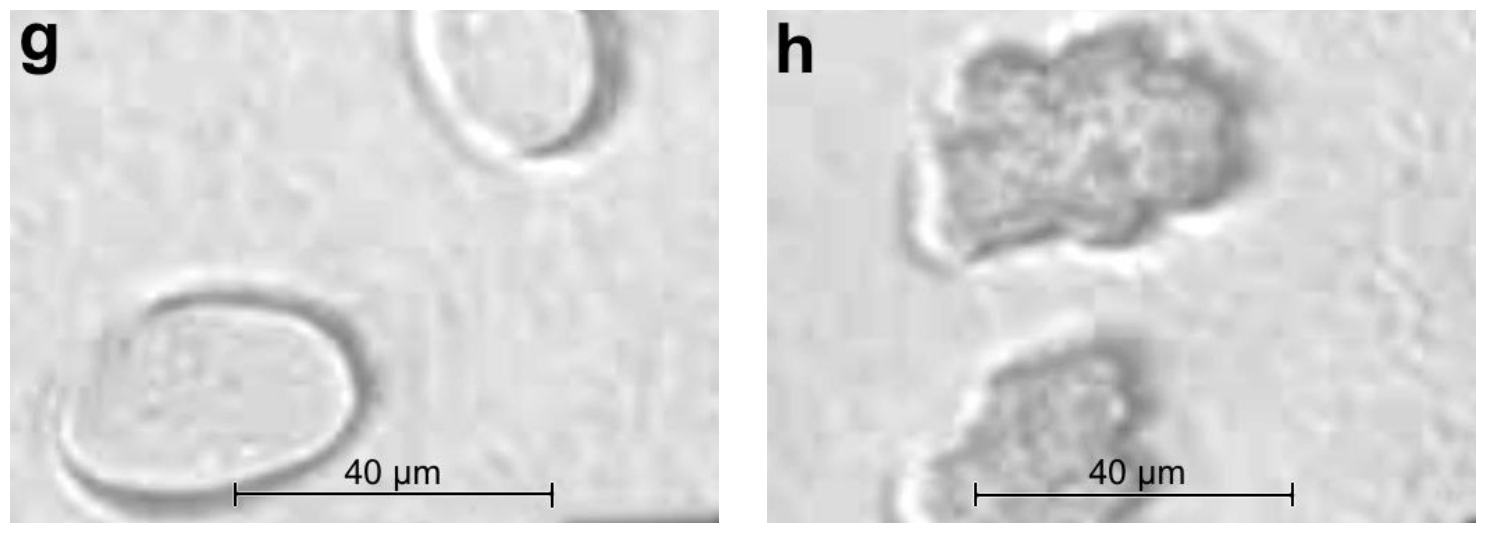

Figure 1. Optical microscope images of the cross-sections of the fibers. (a) Polyester $\mathrm{Craque}^{\circledR}$, (b) Polyester Finecool ${ }^{\circledR}$, (c) Polyester Coolmax ${ }^{\circledR}$, (d) Polyester Holofiber ${ }^{\circledR}$, (e) Polyester Airclo ${ }^{\circledR}$, (f) Polyester Trevira ${ }^{\circledR}$, (g) Viscose Seacell ${ }^{\circledR}$, (h) Viscose Craque $^{\circledR}$,

It is well known that the type of fibre, yarn properties, fabric structure, finishing treatments and clothing conditions are the main factors affecting thermo-physiological comfort. ${ }^{18}$ As reported in Table 1, the characteristic of the knitted fabrics used in this study are very similar in terms of yarn linear density (2.4 dtex), courses/cm (15 \pm 1$)$, wales/cm (22 \pm 2$)$, mass (173 \pm $16)$, thickness $(0.8 \pm 0.1)$ and loop length $(2.7 \pm 0.1)$ showing differences of maximum $10 \%$ of amplitude. Although the loop length of each fabric could maximum vary by less than $1 \%$, the other measurements could vary over a range of $25 \%$ (off-machine, full wet, dry static, stretched). In our case the internal repetitions ( 3 for each sample) are not so dramatic because the fabrics were handled carefully to minimize errors through distortion or premature relaxation, and are similar to the $10 \%$ difference between the different samples. Thus, the differences observed during the characterization of the studied knitted fabrics were mainly due to the morphologies and imbibed materials of the yarns and not to the fabric structure.

\subsection{Thermal properties}

In Figure 2 can be observed the measured thermal conductivities. Thermal conductivity is anintensive property of a material that represents the heat transfer process through a fabric. Thermal conductivity $(\lambda)$ can be expressed by the following equation: $\lambda=Q h / A \Delta T$, where $\lambda$ is the thermal conductivity $(\mathrm{W} / \mathrm{mK}) ; \mathrm{Q}$, the amount of heat $(\mathrm{J}) ; A$, the area through which heat is conducted $\left(\mathrm{m}^{2}\right) ; t$, the time of conduction (s); $\Delta \mathrm{T}$, the drop of temperature; and $\mathrm{h}$, the fabric thickness $(m)$. It is the flux of heat (energy per unit area per unit time) divided by the temperature gradient. It is defined as the measure of conducted heat pass though unit thickness under $1 \stackrel{\circ}{ } \mathrm{C}$ heat difference. According to test results, analysed polyester fabrics in 
this study, have similar thermal conductivity with the exception of the Holofiber ${ }^{\circledast}$ yarn that show the highest value among polyester yarns probably due to the higher areal mass of this fabric. Exists a direct correlation between thermal conductivity and fabric areal mass, when the fabric area mass increases, the thermal conductivity also rises because of the lower amount of air gaps. ${ }^{19}$ Therefore as the amount of entrapped air in the structures decreases the fabric provides lower thermal insulation with higher thermal conductivity values. However, It is not clear in which extent the imbibed material in the Holofiber ${ }^{\circledR}$ yarns contribute to the rise in the areal mass and thermal conductivity.

The thermal conductivity of the SeaCell ${ }^{\circledR}$ viscose sample is quite high as expected for regenerated cellulose-based fibres. ${ }^{20}$ However, the viscose control sample shown a lower thermal conductivity than that of the Seacell ${ }^{\circledR}$ sample. It seems that the air entrapped in the irregular channelled structure of conventional viscose yarn caused low thermal conductivity.

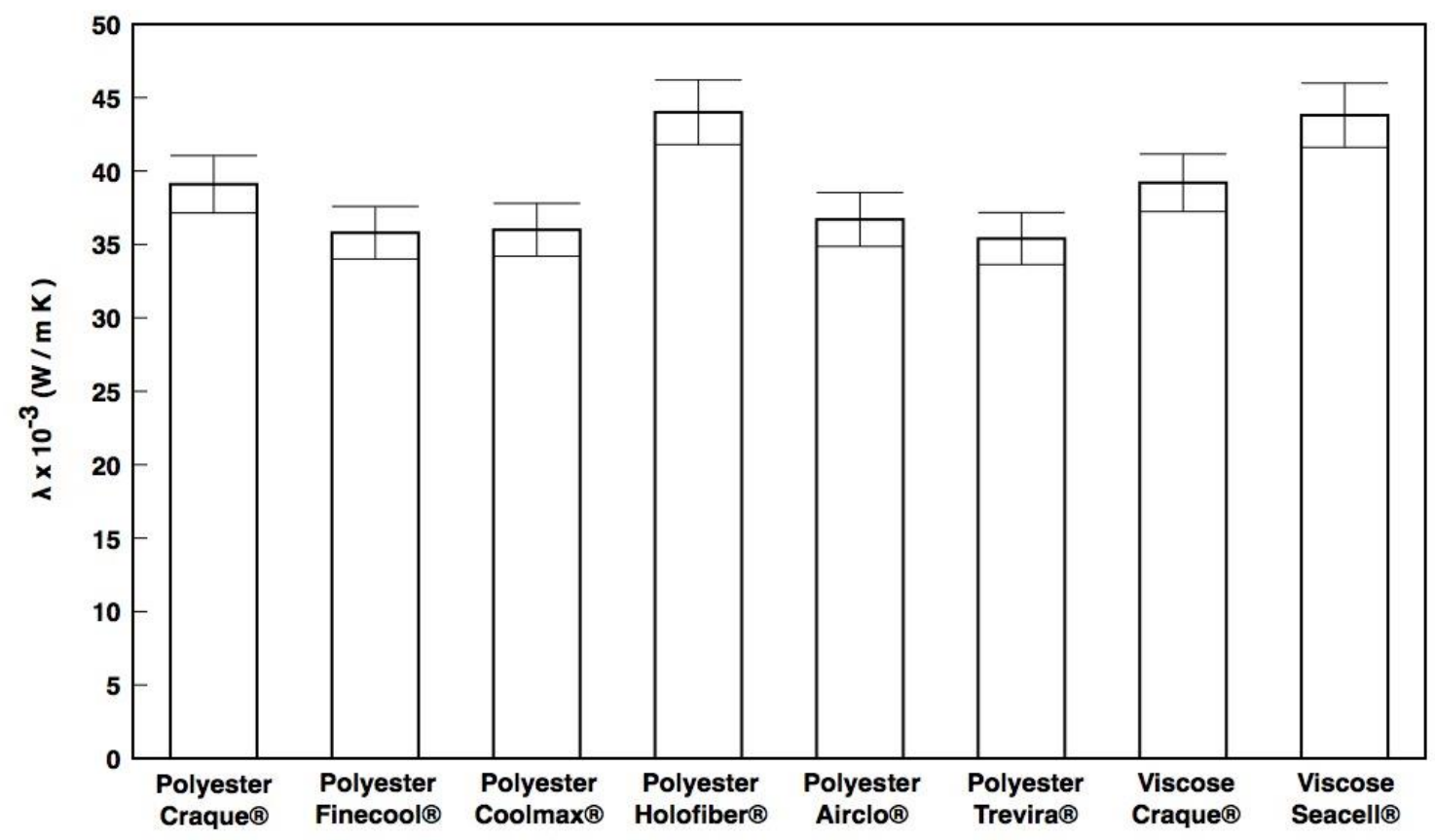

Figure 2. Thermal conductivity values of the knitted fabrics.

Thermal resistance expresses the thermal insulation of fabrics and is inversely proportional to thermal conductivity. Thus the thermal resistance of a fabric represents a quantitative evaluation of how good the fabric is in providing a thermal barrier. In a dry fabric or containing very small amounts of water it depends essentially on fabric thickness and, to a lesser extent, on fabric construction and fibre conductivity. In Figure 3 the studied fibres showed a great variety of thermal resistances however the fabric thickness are very similar $(0.8 \pm 0.1 \mathrm{~mm})$. This could be explained with the higher value of thermal conductivity property of the material and 
fabric conformations. ${ }^{21}$ The knitted fabrics made with Airclo $^{\circledR}$ and Finecool ${ }^{\circledR}$ yarns display the highest values of thermal resistance because of higher amount of air in the fabric structure that slow the heat transfer process. The air in the hollow Airclo ${ }^{\circledR}$ fibres and the inter-fibre spaces of the small Finecool ${ }^{\circledR}$ yarns acts as an insulator in the fabric. ${ }^{22}$

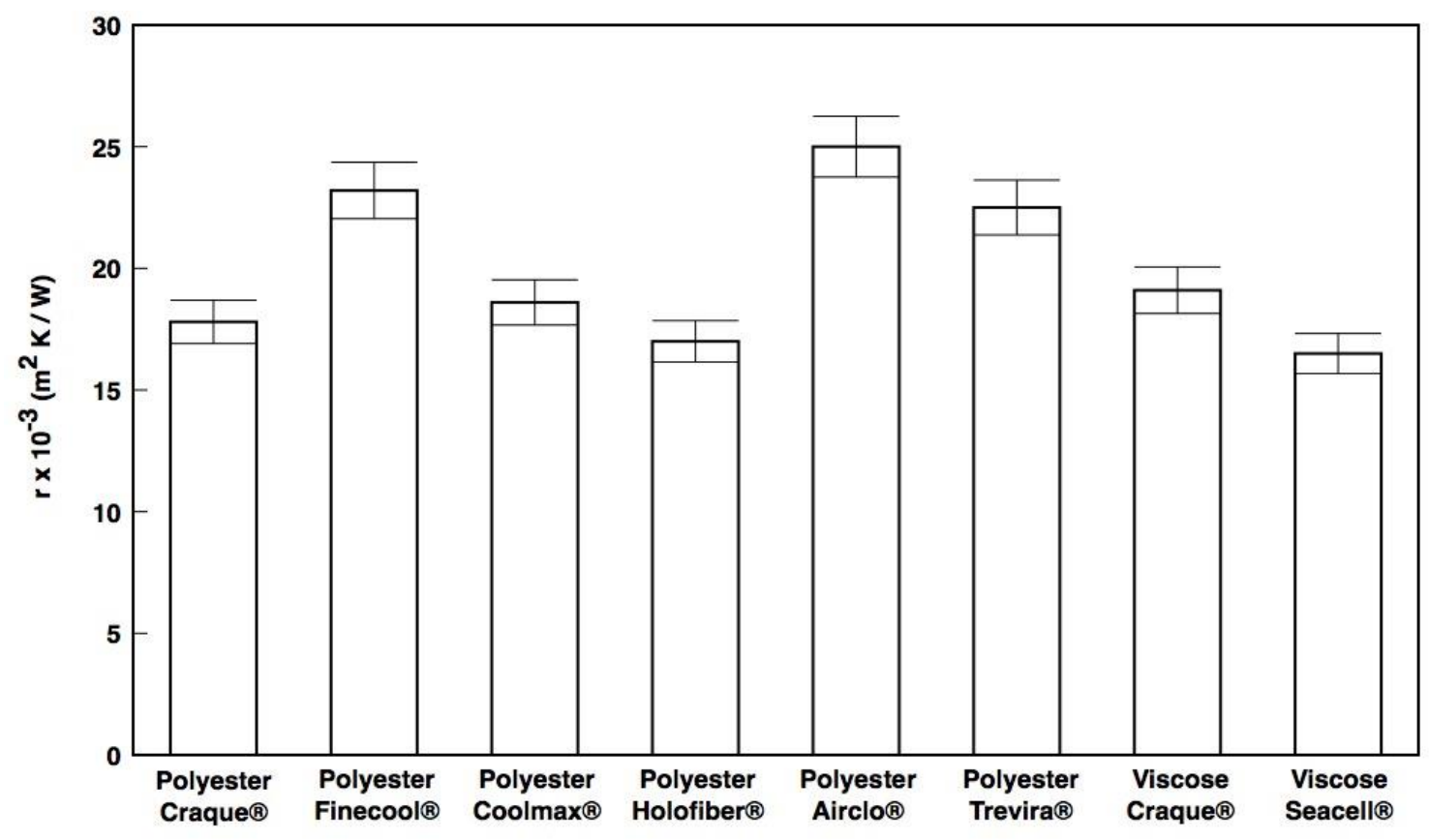

Figure 3. Thermal resistance values of the knitted fabrics.

Thermal diffusivity is the ability related to the heat flow through the fabric structure. Thermal diffusivity is defined by the equation: $a=\lambda / \rho c$; where $a$ is the thermal diffusivity $\left(\mathrm{m}^{2} / \mathrm{s}\right) ; \lambda$, the thermal conductivity $(\mathrm{W} / \mathrm{mK}) ; \rho$, the fabric density $\left(\mathrm{Kg} / \mathrm{m}^{3}\right)$; and $\mathrm{c}$, the specific heat capacity $\left(\mathrm{JKg}^{-1} \mathrm{~K}^{-1}\right)$. Thermal diffusivity plays an important role in the transient-state heat transfer describing how fast heat propagates through a fabric. Material with high thermal diffusivity will respond quickly to changes, reaching faster a new equilibrium condition. All the studied polyester fabrics display higher thermal diffusion than viscose fabrics (Figure 4). Airclo ${ }^{\circledR}$ and Finecool ${ }^{\circledR}$ yarns show the highest thermal diffusivity. In fibres with high thermal diffusivity, heat moves rapidly through the material, and does not require much energy from its surroundings to reach thermal equilibrium..$^{23}$ Conversely, viscose Seacell ${ }^{\circledR}$ displays the lowest thermal diffusivity mainly due to the higher density of its structure. ${ }^{24}$ 


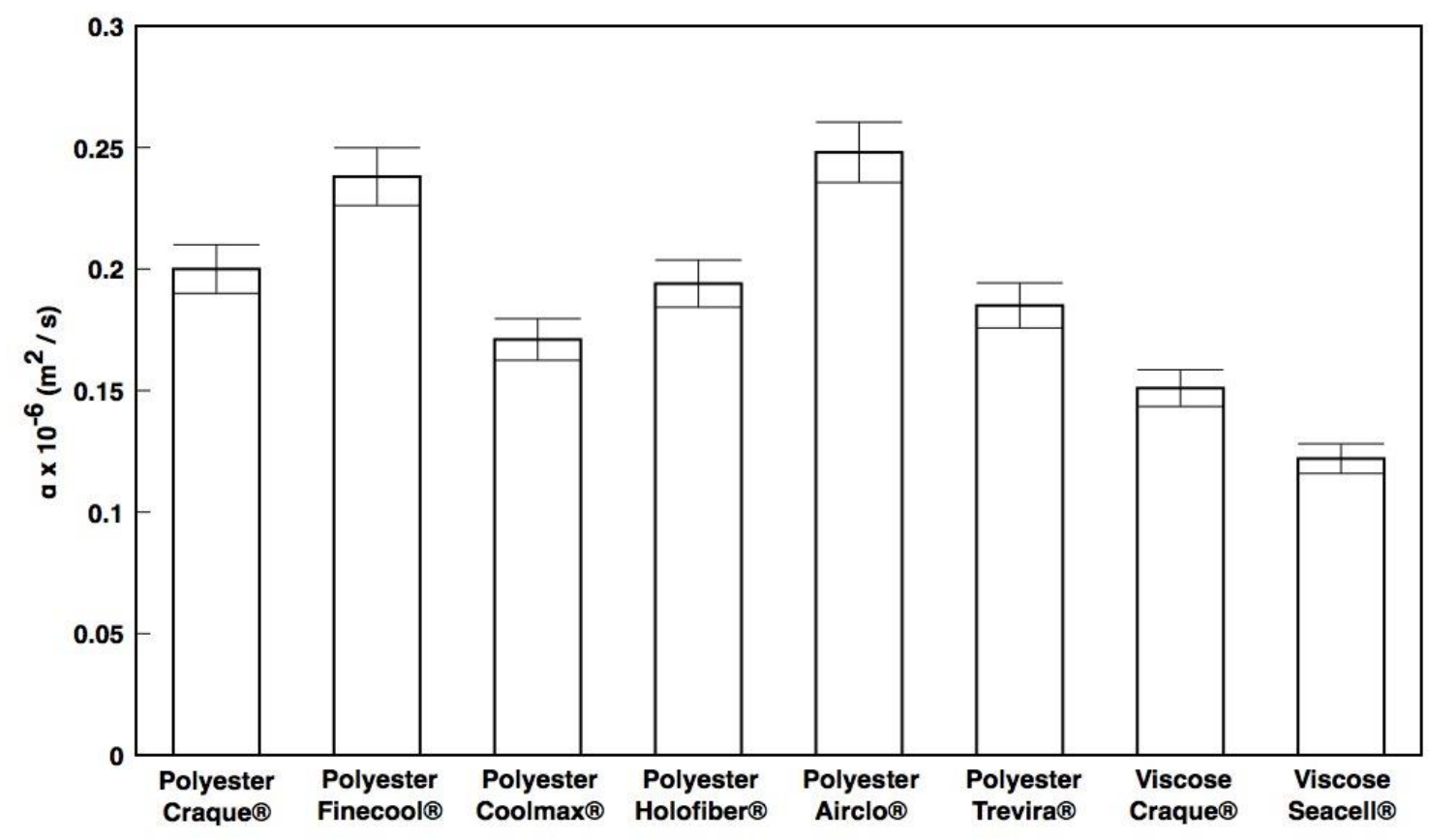

Figure 4. Thermal diffusivity values of the knitted fabrics.

Theoretically, substances with higher thermal diffusivity would record the least radiation absorptivity at any particular time. Thermal absorptivity is the objective measurement of the warm-cool feeling of fabrics and is a surface-related characteristic. Thermal absorptivity of a material is the thermal property associated with insulation of a material. Thermal absorptivity is related to fabric conductivity, density and specific heat capacity, as it is clear from equation: $\mathrm{b}=\sqrt{\lambda \rho c}$, Where $\mathrm{b}$ is the thermal absorptivity $\left(\mathrm{Ws}^{1 / 2} / \mathrm{m}^{2} \mathrm{~K}\right) ; \lambda$, the thermal conductivity $(\mathrm{W} / \mathrm{mK}) ; \rho$, the fabric density $\left(\mathrm{Kg} / \mathrm{m}^{3}\right)$; and c, the specific heat capacity $\left(\mathrm{JKg}^{-1} \mathrm{~K}^{-1}\right)$. The more heat that a material absorbs, the less it reflects and vice versa. When a human touches a garment that has a different temperature than the skin, heat exchange occurs between the hand and the fabric. If the thermal absorptivity of clothing is high, it gives a cooler feeling at first contact with the skin. ${ }^{18}$ The surface character of the fabric greatly influences this sensation and yarn characteristics play a significant role on thermal absorptivity. ${ }^{21}$ Viscose Seacell ${ }^{\circledR}$ fabrics, display the highest thermal absorptivity values, providing the coolest feeling at the beginning of skin contact (Figure 5). This situation is explained by the used yarn but also by the surface area between the fabric and skin that is bigger for smooth fabric surfaces. Thermal absorptivity value decreases while the yarn is getting finer. For this reason fabrics knitted with Finecool ${ }^{\circledR}$ yarns will give a warmer feeling at first contact. Fabrics knitted with Airclo ${ }^{\circledR}$ hollow yarns display the lowest thermal absorptivity values because of the high amount of air of this yarn. ${ }^{25}$ 


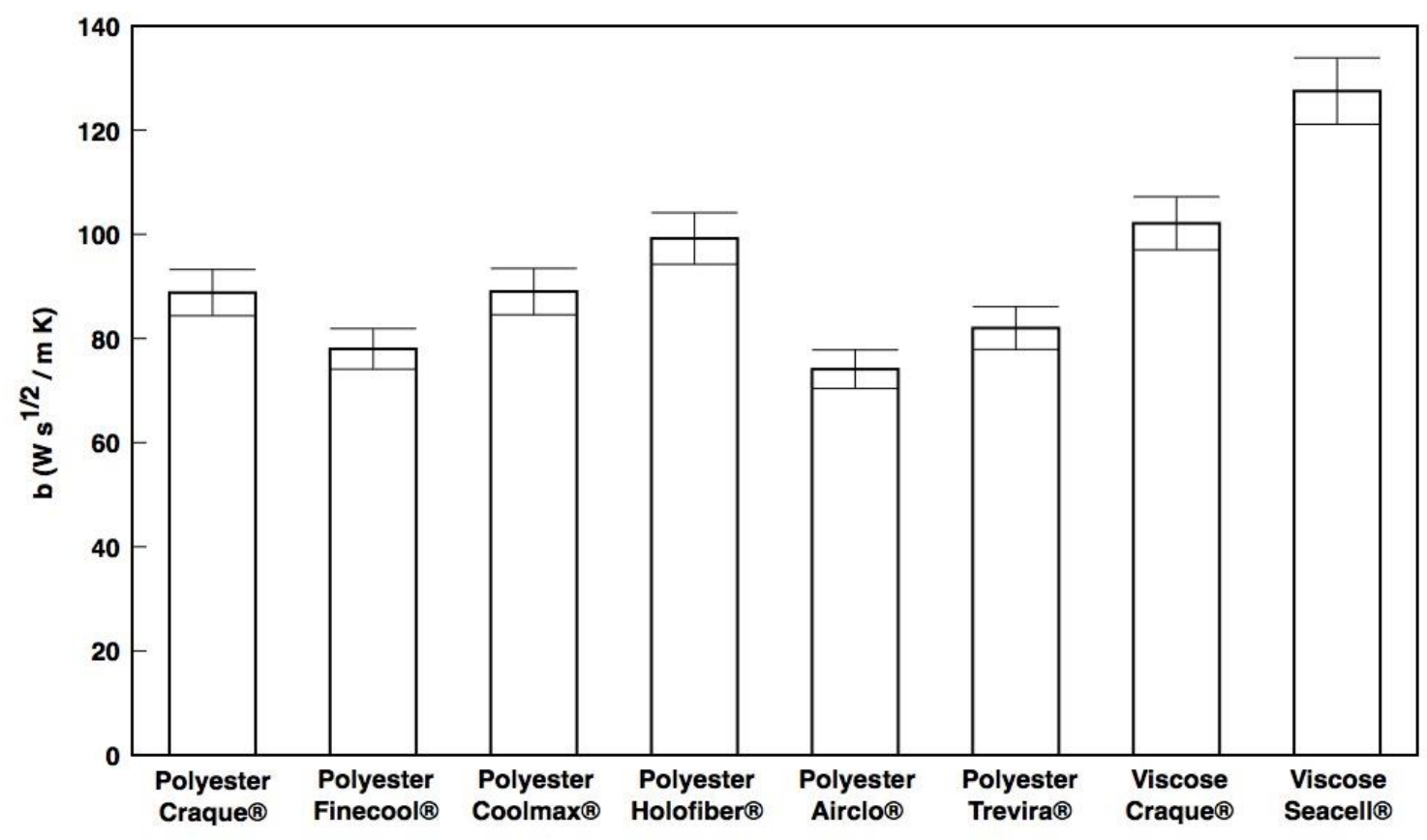

Figure 5. Thermal absorptivity values of the knitted fabrics.

The mechanisms of heat transfer through textile fabrics may involve conduction through air and fibres, radiation and convection within the fabric. It is stated that the mechanisms of heat transfer through textile fabrics depend mainly on thermal conduction and radiation; ${ }^{26}$ however, the portion of heat flow transferred by radiation does not exceed $20 \%$ of the total heat f1ow. Hence, the thermal conductivity is the dominant property to determine the heat transfer through fabrics and garments. ${ }^{27}$ The higher the thermal conductivity the greater is the heat flux. At this point, it can be concluded that the viscose Seacell ${ }^{\circledR}$ has the higher thermal absorptivity and the higher heat flow (q) as well (Figure 6), indicating a relatively cooler feeling when it touches human skin for a few seconds, which may give a more pleasant feeling compared to polyester yarns. ${ }^{28}$ In general terms, it can be stated that viscose sample has the lowest while polyester Airclo $^{\circledR}$ the higher thermal insulating properties. 


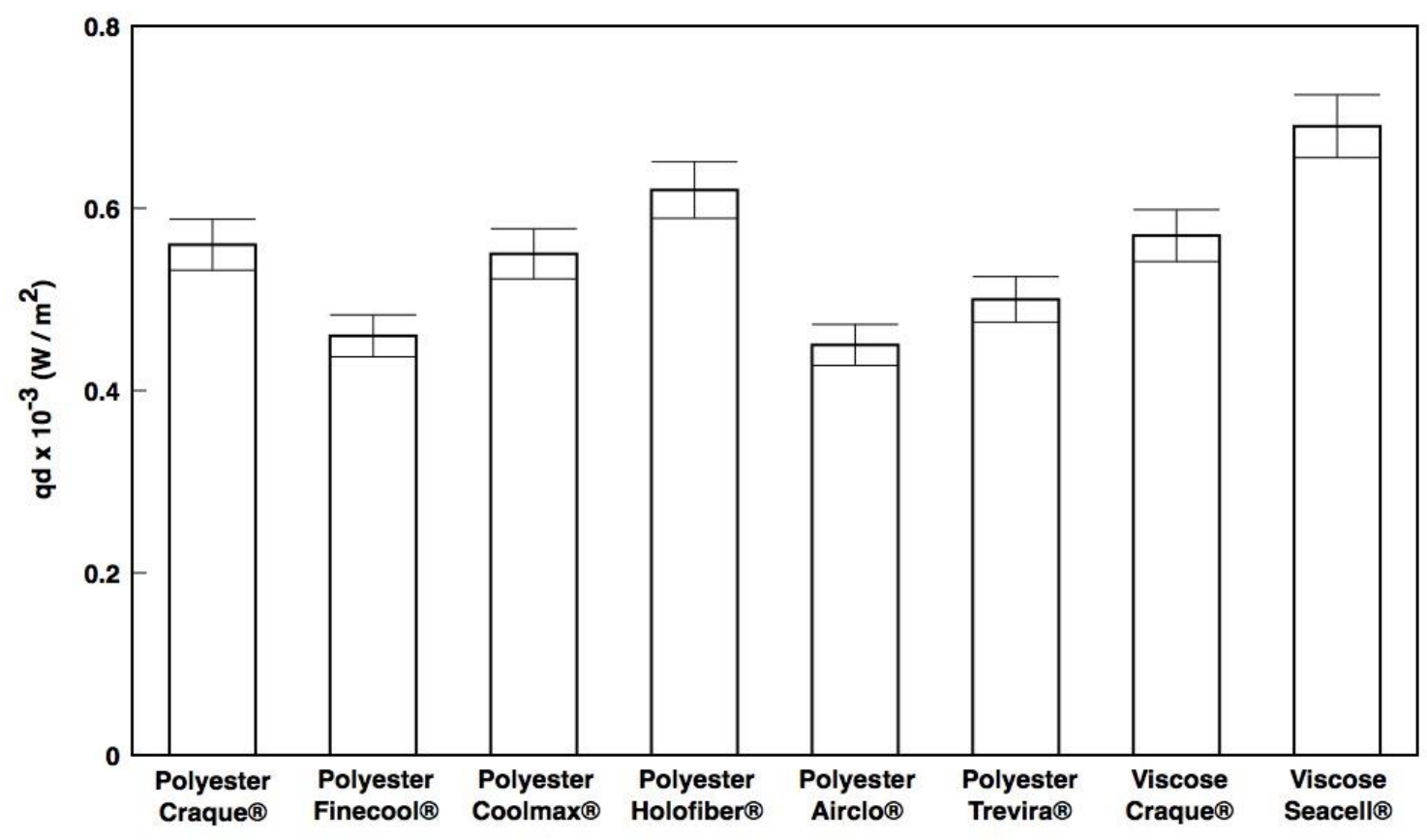

Figure 6. Heat flow values of the knitted fabrics.

\subsection{Air permeability}

The air permeability of the fabrics is depicted in figure 7. Air permeability is described as the rate of airflow passing perpendicularly through a known area, under a prescribed air pressure differential between the two surfaces of a material. ${ }^{21}$ All textile fibres irrespective of their chemical composition are impermeable to air and therefore the passage of air through a fabric can only take place through space between the fibres and between the yarns. ${ }^{29}$ The air permeability is mainly affected by the characteristics of pore in the fabric. The main factors affecting the porosity of the fabrics are the yarn linear density, yarn diameter, course density and wale density. ${ }^{22}$ However, in this work the fabric structures are very similar in thickness, loop lengths, course density and wale density. The fibre morphology and deformability seem the most important factors facilitating the passage of air through the fabric. ${ }^{30}$ Fabrics made from looser or less dense yarns such as Finecool $^{\circledR}$ and Airclo ${ }^{\circledR}$ polyesters show higher air permeability than dense and structural complicated polyesters such as Coolmax ${ }^{\circledR}$ (oblong in cross-section with grooves running lengthwise along the threads) and Holofiber ${ }^{\circledast}$ (PET that contains an optical responsive material). ${ }^{31}$ Seacell ${ }^{\circledR}$ yarns reduces the air permeability of the knits examined compared with knits manufactured from pure viscose yarns, where the linear density is the same, as previously observed..$^{32}$ In general, the air permeability of knits seems to depend on the linear density and raw material composition. However, in this study, there exists a good relationship between area density and air permeability for all the kinds of knits examined. 


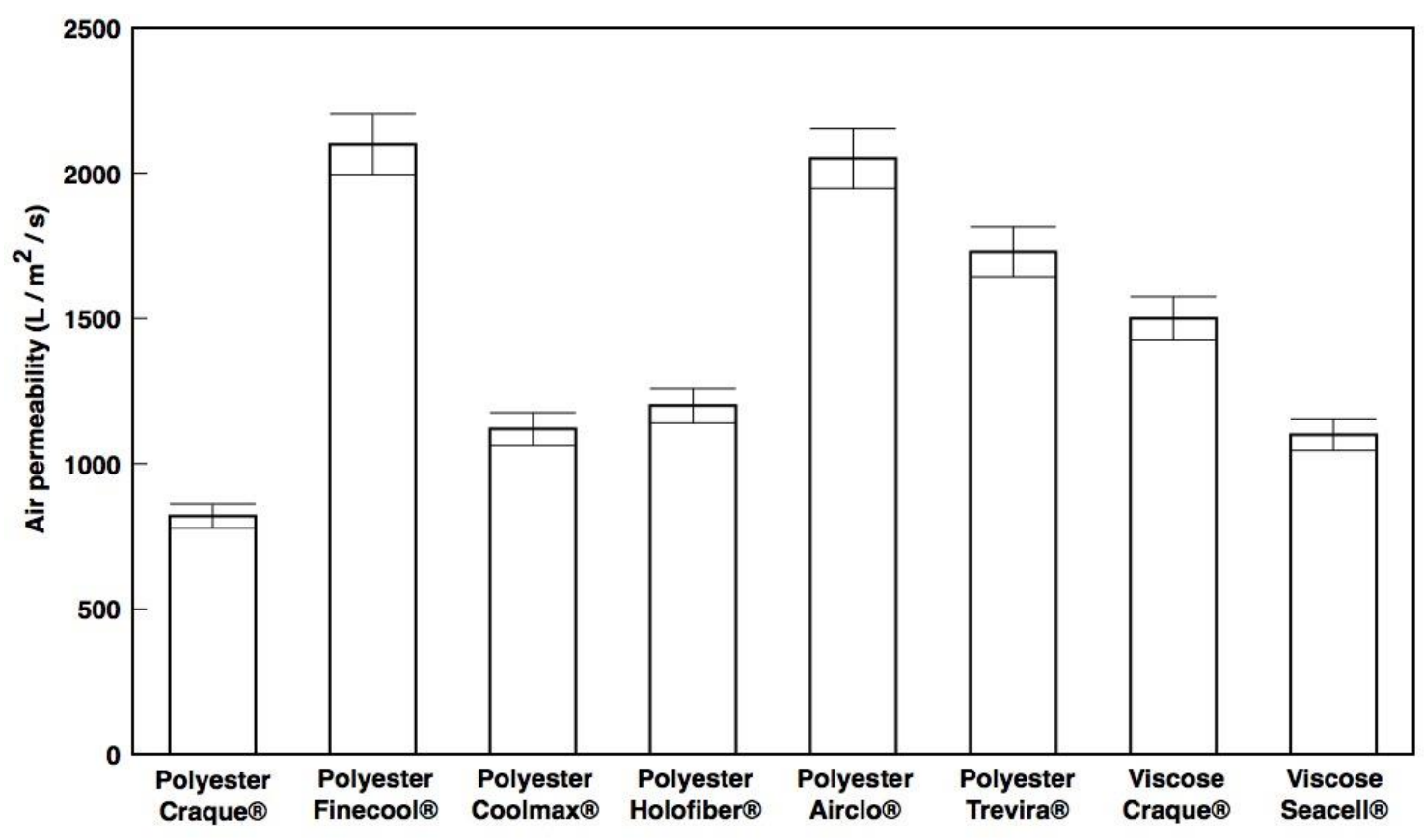

Figure 7. Air permeability values $\left(1 / \mathrm{m}^{2} / \mathrm{s}\right)$ of the knitted fabrics.

\subsection{Water vapour permeability}

Water vapour permeability is the ability to diffuse vapour from the body. The rate at which water vapour moves through a fabric plays an important role in determining the comfort as it influences the human perception and the cool/warmth feeling. To have excellent comfort it is not how much water that is absorbed by the fibre rather how much moisture vapour the fibre is able to transport that is most important. ${ }^{33}$ In other words after the body has stopped sweating, the textile fabric should release the vapour held to the atmosphere in order to reduce the humidity on the surface of the skin. ${ }^{34}$ When vapour passes through a textile layer two processes are involved: diffusion and sorption-desorption. In the case of diffusion along the fibre, water vapour diffuses from the inner surface of the fabric to the fibres' surface and then travels along the interior of the fibres and its surface, reaching the outer fabric surface. At a specific concentration gradient, the diffusion rate along the textile material depends on the porosity of the material and also on the water vapour diffusivity of the fibre. Diffusivity of the material increases with the increase in moisture regain. In the same way, moisture transport through sorption-desorption process will increase with the hygroscopicity of the material. ${ }^{35}$ Water vapour permeability depends on the structure of knits not in the same order as air permeability. Previous studies have demonstrated that there is no correlation between fabric air permeability and its water vapour permeability. ${ }^{36,37}$ On the other hand, it was found that the fabric weight was significantly correlated with its water vapour resistance. ${ }^{38}$ The water 
vapour permeability is highly dependent on the macroporous structure of fabric, especially in low-density open textile structures. When comparing fabrics made of the same yarn, the water vapour transmission rate is primarily a function of fabric density. Moreover, fibre-related factors, such as cross-sectional shape and moisture absorbing properties, do not play a significant role. Thus, the higher water vapour permeability of Finecool ${ }^{\circledR}$ fabrics can be attributed to the lower values of areal mass. ${ }^{39}$ Fabric produced with conventional polyester have the smallest water vapour permeability values while Trevira ${ }^{\circledR}$ polyester fabrics have the higher water vapour permeability due to the silver nanoparticle functionalization that change the fibre morphology giving an hygroscopic behaviour to Trevira $^{\circledR}$ polyester fibres. As illustrated in Figure $8 \mathrm{Coolmax}^{\circledR}, \mathrm{Holofiber}^{\circledast}$ and $\mathrm{Airclo}^{\circledR}$ fabrics structures with higher densities and peculiar cross-sectional shapes showed lower indexes of water vapour transmission rate than Trevira ${ }^{\circledR}$ and Finecool ${ }^{\circledR}$ yarns. However, their values are not so low as for the conventional polyester. ${ }^{21}$ Also Viscose yarns display high values of water vapour transmission rates. Viscose fibres are hygroscopic and the water vapour transportation of these fabrics is mainly ruled by the raw material characteristics. The hygroscopic character of viscose decreases the resistance to vapour flow through the fibre surface and the water vapour transportation seems mainly due to the size and number of pores of the fabric structure.

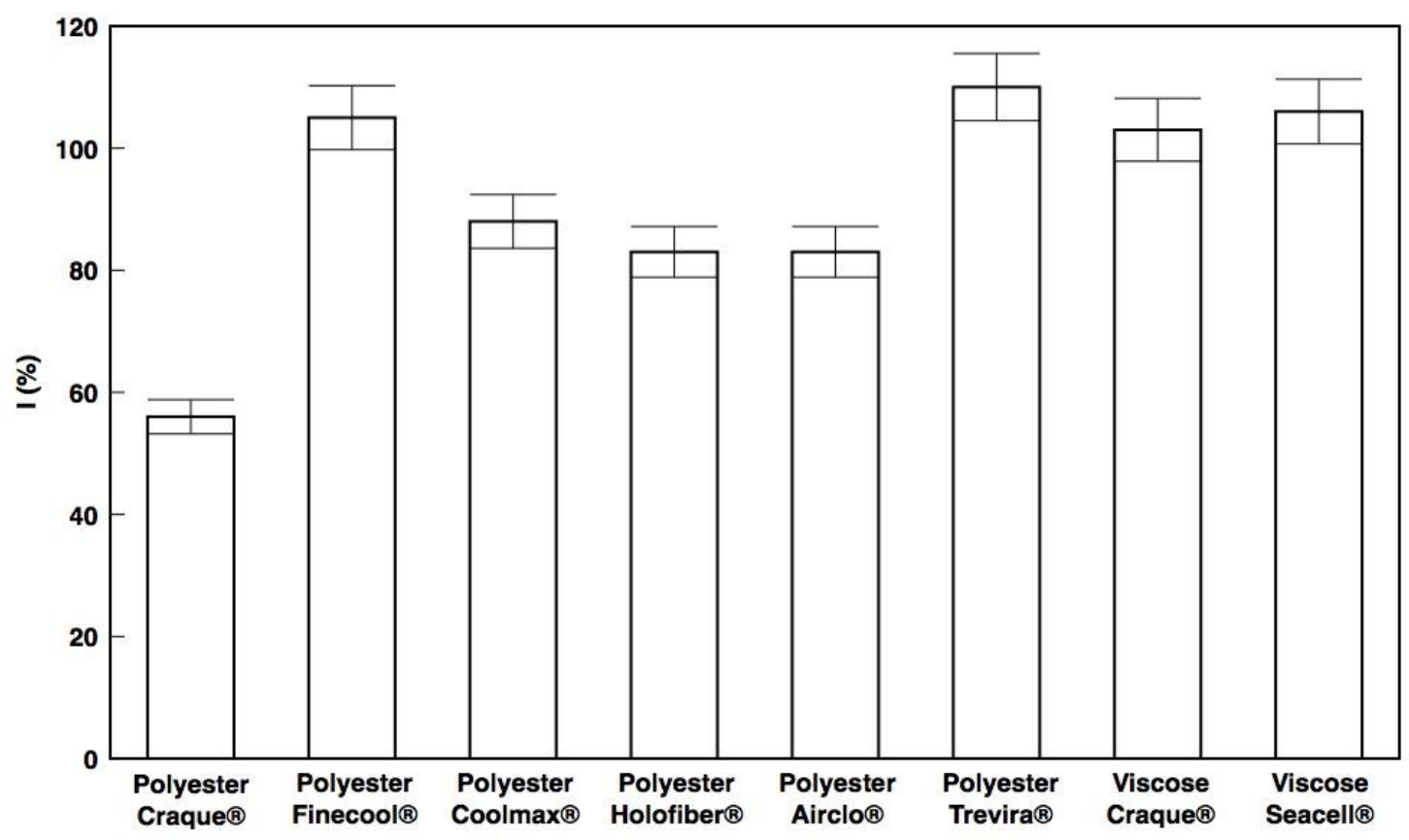

Figure 8. Water vapour permeability values (\%) of the knitted fabrics.

\subsection{Surface friction}

Mechanical properties like roughness of fabric surface are responsible for non-specific skin 
reactions like wool intolerance or keratosis follicularis. ${ }^{40}$ The surface of a textile fabric is not uniformly flat and smooth and knitted fabrics are rarely balanced in terms of appearance of course-wise and wale-wise directions on their surface. Despite the coefficient of kinetic friction alone may be insufficient for surface characterization generally a smooth fabric is the one that possesses a low coefficient of kinetic friction. ${ }^{41} \mathrm{An}$ increase in linear yarn density and diameter could increase frictional resistance and surface roughness. ${ }^{42}$ It is observed from all knitted fabric samples in Figure 9 that Finecool ${ }^{\circledR}$ polyamide fabric has the highest coefficient of kinetic friction and the Holofiber $^{\circledast}$ polyamide fabric has the lowest. Finecool ${ }^{\circledR}$ fibre display a rhomboid cross section that influence negatively the smoothness of the fabric since generally, materials with circular fibre cross-section have a higher degree of softness. Comparison between antimicrobial fabrics and conventional fabrics shows no significant differences. Silver nanoparticles in their polymeric matrix, which might be random distributed all over the fibres seems have no effect in the surface frictional properties.

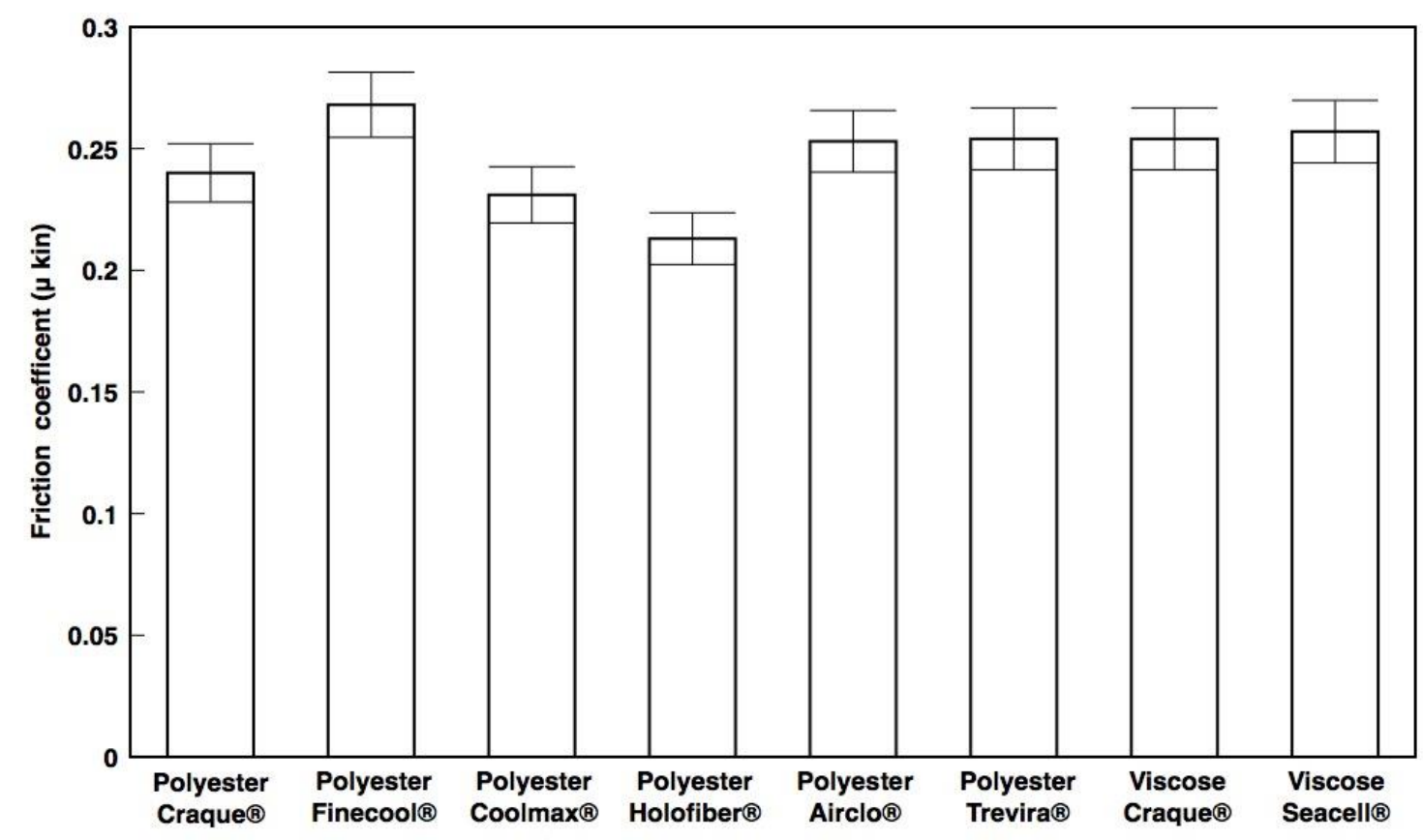

Figure 9. Coefficient of kinetic friction of the knitted fabrics.

\subsection{Wicking tests}

Liquid moisture transportation through textiles is due to a wetting process followed by wicking. Wetting is the initial process of fluid spreading where the fibre-liquid interface replaces fibre-air interface. Wicking is due to fibre-liquid molecular attraction at the surface of the fibre materials, which is determined by the surface tension and the effective capillary 
pathways and pore distribution. ${ }^{43}$ Wicking properties of textile fabrics are also influenced by the surface roughness, the heterogeneity, the diffusion of liquid into the fibre, and by the capillary action of the fibre assemblies. A number of factors, especially fabric structure (yarn count, fabric density, weave design, porosity, fibre content etc.) also affect wicking height. ${ }^{44}$ On one hand, materials based on natural fibres such as viscose are hygroscopic and, therefore, characterised by high absorption levels. However, wetting causes the fabric to swell, changing the capillary space position and the moisture absorbed is bound in strongly and only released slowly increasing the weight of the garment as well as affecting the wicking ability. On the other hand, for most synthetic fabrics, wicking, however, will not take place due to their high contact angles. Since synthetic fibres, such as polyester, are not hygroscopic they only absorb a comparatively small amount of moisture. ${ }^{45}$ For these reasons only polyester yarns were studied for their wicking abilities in this study. Moreover, also the Trevira ${ }^{\circledR}$ polyester yarn was not studied since its primary purpose is the antimicrobial properties and not the thermal properties and moisture management. Knitted fabrics made by using microfiber polyester show excellent moisture-related comfort properties since small size of capillary increases the capillary pressure which drives the water transfer in to the capillaries and results in higher wicking. ${ }^{22}$ In general, the faster a fabric can wick moisture, the more surface area the moisture covers, in turn allowing the evaporation of the moisture to occur faster leaving the wearer dry and comfortable. In order to have a term of comparison the minimum quality values of the AATCC 197 vertical wicking test method and the AATCC 198 horizontal wicking test methods for knit fabrics were used to compare the relative performance in moisture management. In AATCC 197 for effective vertical wicking water should travel at least $10 \mathrm{~cm}$ (4 inches) in 10 minutes. In AATCC 198 for effective horizontal wicking at least $0.035 \mathrm{~g} /$ second ( $2.1 \mathrm{~g} /$ minute) of water should be absorbed in a knit fabric. From Figures 10, it can be seen that, after ten minutes, in both course- and wale-wise directions, only the vertical wicking height of the fabric Coolmax ${ }^{\circledR}$ reach the AATCC requirement of $10 \mathrm{~cm}$. The wicking height of the fabric Holofiber ${ }^{\circledast}$ is the lowest due to the optical responsive material present in the Holofiber ${ }^{\circledR}$ that affects negatively the capillarity of the polyester fibres. Moreover, Figures 11 indicates that the horizontal wicking ability of Coolmax ${ }^{\circledR}$ fabric has the highest water absorption in the first minute (Coolmax absorb twice as much water as Finecool) but after 5 minutes displays the same value of the other polyester fabrics with the exception of the Holofiber ${ }^{\circledR}$ fabric that also in this case displays very low wicking ability. This behaviour can be attributed to the Coolmax ${ }^{\circledR}$ fabric's contact angle and to its irregular cross-sectional shape yarns forming more capillaries than the others yarns. Yarns with higher shape factor have better wicking rate due to their higher specific surface area. As soon as the fabric comes into contact with water, wicking and 
water absorbency cannot be separated and are simultaneous. ${ }^{46}$ It is clear that the wicking ability of the knitted fabrics is more influenced by the geometry of the fibre than to the dimensional properties.
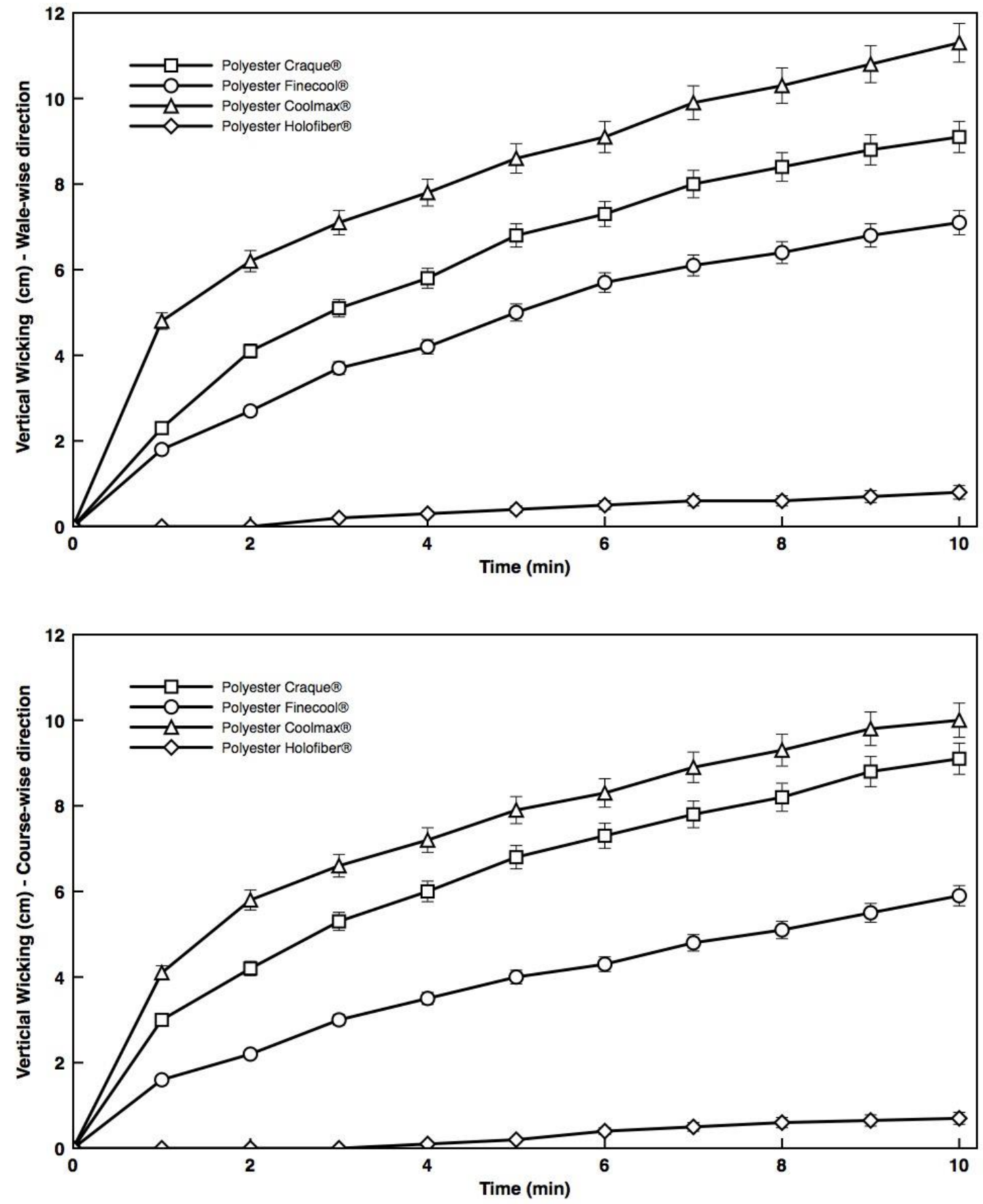

Figure 10. Vertical wicking values in wale-wise and course-wise directions of the polyester knitted fabrics. 


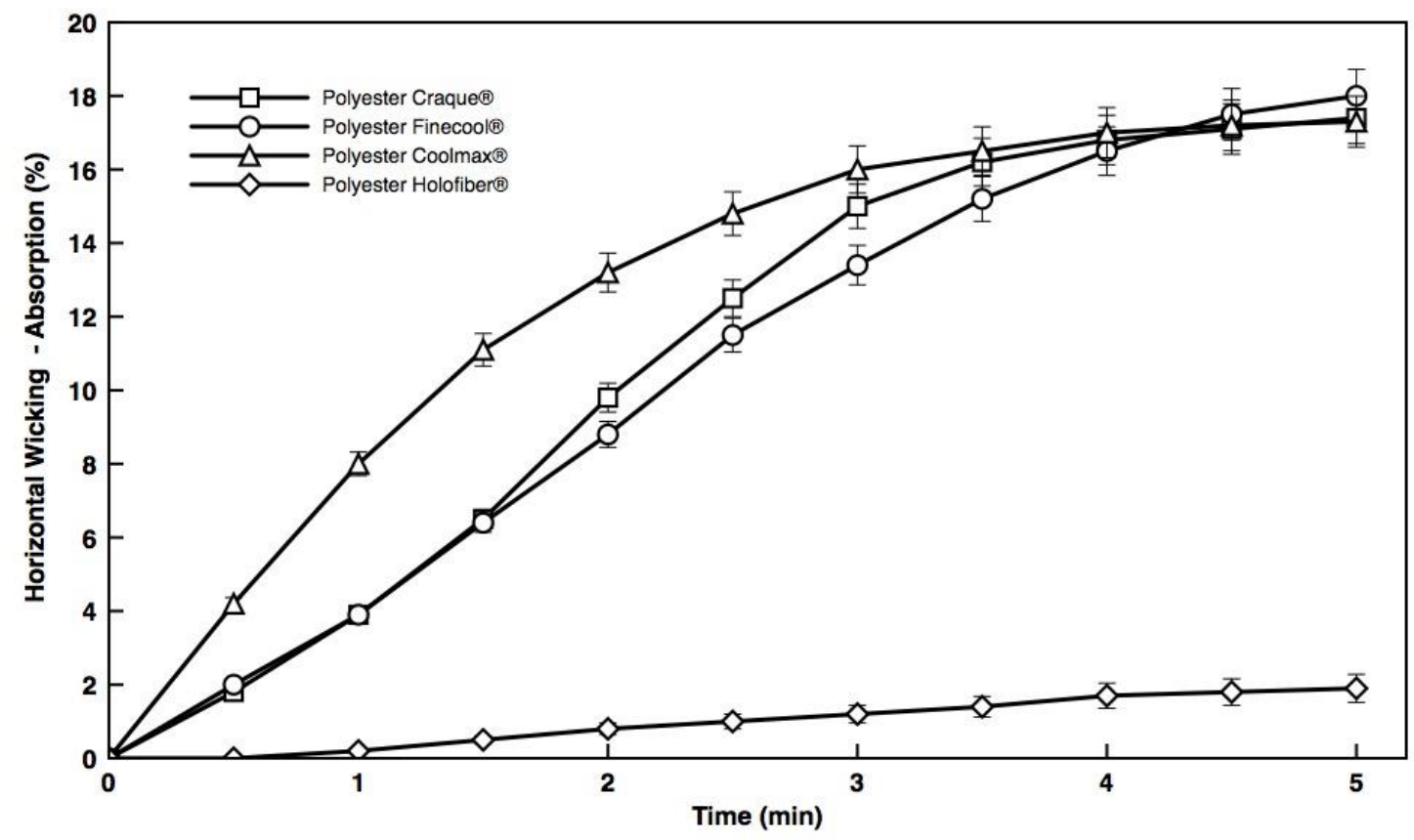

Figure 11. Horizontal wicking values of the polyester knitted fabrics.

\subsection{Drying capability}

The evaporation curves presented in Figure 12 demonstrate that at $20{ }^{\circ} \mathrm{C}$ in the first 15 minutes all the fabrics display the same behaviour. After 30 minutes the drying rates of Coolmax $^{\circledR}$ fabrics are higher than the other polyester yarns. Holofiber ${ }^{\circledR}$ shows the higher remaining water ratio. The first part of the curve corresponds to moisture release from the void spaces between yarns and the second part corresponds, as in the case of Coolmax ${ }^{\circledR}$ fabrics, to the release of moisture retained in the inter-fibre capillaries. ${ }^{21}$ In polyester water is not absorbed too much inside the yarns, because of the hydrophobic nature of the material. Polyester fabric gets dry sooner than other fabric, but the level of heat losses during the evaporation is higher due to the presence of continuous water film with higher thermal conductivity. ${ }^{47}$ Wicking ability and moisture regain play an important role in the drying capability of the fabric. Due to the high number of hydroxyl groups available for bonding with water in viscose, its moisture regain is much higher than any other knit back yarn and was not considered in this work to assess the drying ability. ${ }^{46}$ In the first 5 minutes at 37 으 Holofiber ${ }^{\circledR}$ performs as well as Coolmax ${ }^{\circledR}$ and Finecool ${ }^{\circledR}$ or even better but it maintains a greater amount of liquid on the fibre reporting $25 \%$ of water after 30 minutes while the other fibres reach zero water content after 20 minutes of exposure. The lower performance of $\mathrm{Coolmax}^{\circledR}$ at $37 \stackrel{\circ}{\mathrm{C}}$ in the first minutes could be explained by the higher kinetic release of moisture induced by the higher temperature. Differently to the $20 \stackrel{\circ}{ } \mathrm{C}$ tests the moisture release from the void space between yarn is very fast exacerbating the effect of the evaporation of the moisture retained 
in the inter-fibre capillaries. As previously observed for the wicking properties also in this case the optical responsive material present in the Holofiber ${ }^{\circledR}$ affect negatively the drying ability of the fabric at 37 으. For all samples, the performance of release of moisture is considerably better at the internal body temperature than at room temperature.
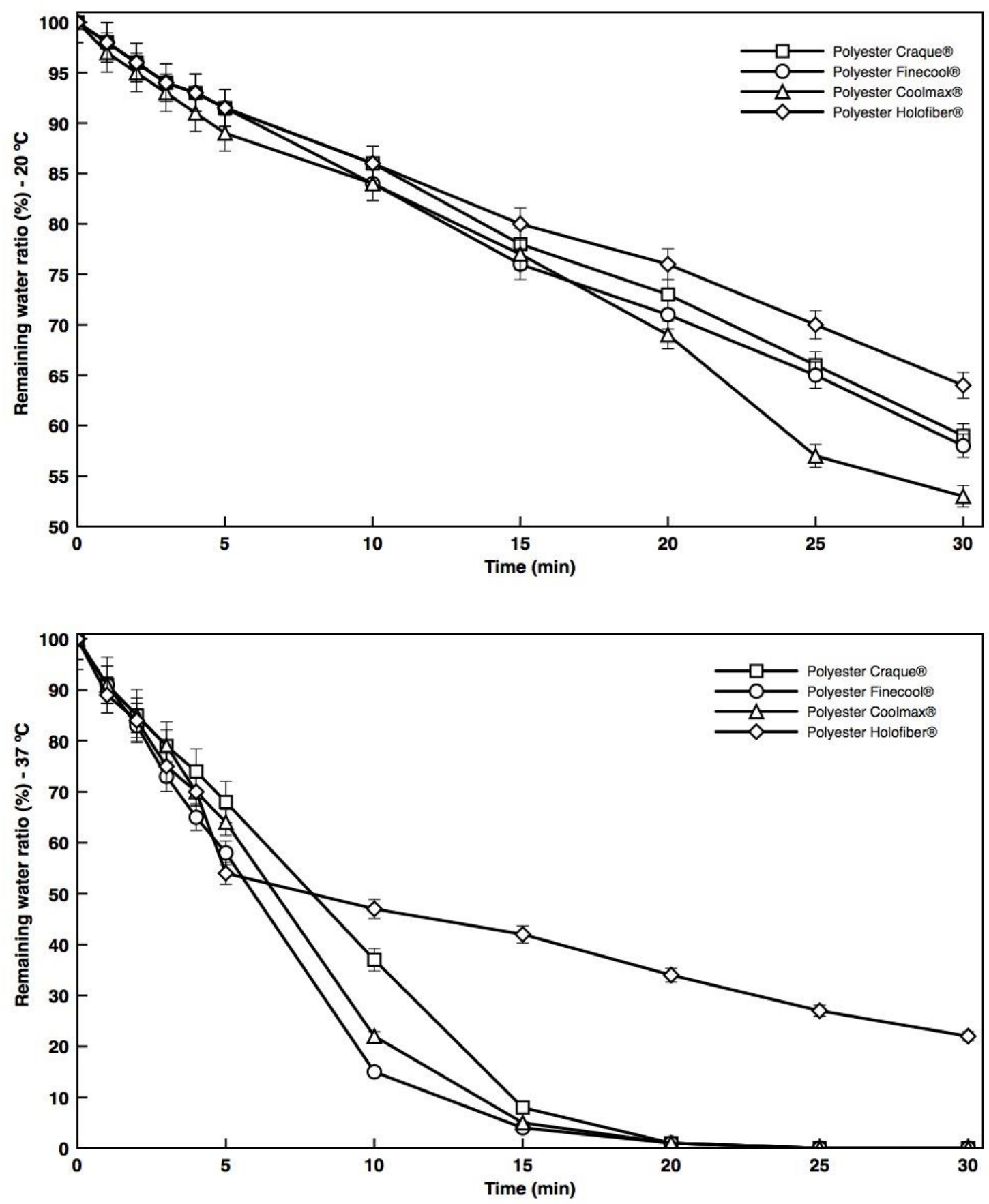

Figure 12. Remaining water ratio values at 20 and $37^{\circ} \mathrm{C}$ of the polyester knitted fabrics. 


\subsection{Antimicrobial assay}

Along with climate and physical activity, textiles have an effect on sweating and the development of odours. The development of body odour itself cannot be avoided, even with optimally designed clothing. Therefore, the use of antimicrobial textiles with the aim of reducing odour by decreasing the number of germs on the skin is an effective approach. ${ }^{48}$

Effectiveness of antimicrobial fabrics against Staphyloccocus aureus, Staphyloccocus epidermidis, Epidermophyton sp., Tricophyton mentagrophytes and Cândida albicans were assessed after different number of washing cycles and presented in table 2 . The percentage of microbial growth reduction for for Trevira ${ }^{\circ}$ and Seacell ${ }^{\circ}$ fabrics decreased after 15 washing cycles. Staphyloccocus aureus showed the highest loss in antimicrobial activity displaying $53.5 \%$ and $84.7 \%$ (from $80 \%$ and $98 \%$ ) of microbial reduction for Trevira ${ }^{\circ}$ and Seacell ${ }^{\circ}$ fabrics, respectively. All the other microorganisms after 15 washing cycles display a reduction in antimicrobial activity of about $10 \%$. In all cases Seacell ${ }^{\circledR}$ fabrics displayed better antimicrobial performance than Trevira ${ }^{\circledR}$ fabrics. This outcome, could be attributed to the outside layer of alginic acid of the SeaCell ${ }^{\circ}$ viscose yarns, which controls the release of the Ag ions. This layer barrier enhances the durability of the antimicrobial activity of these fibres resulting in bactericidal and fungicidal enhancement effects. It can be concluded from the data presented in table 2 that Seacell ${ }^{\circ}$ fabric has the best washing fastness confirming that barrier layers are an important parameter to control the release of silver ions. ${ }^{49} \mathrm{All}$ the other fabrics used in this work were also tested for antimicrobial activity showing no microbial growing inhibition. 
Table 2. Percentage of bacterial and fungal inhibition on antimicrobial fabrics after applying different number of washings. Data represent mean values \pm SD $(n=3)$.

\begin{tabular}{|c|c|c|c|c|c|c|c|c|c|c|c|c|c|c|c|}
\hline \multirow{5}{*}{ Materials } & \multicolumn{15}{|c|}{ Microrganism } \\
\hline & \multicolumn{3}{|c|}{ Staphyloccocus } & \multirow{2}{*}{\multicolumn{3}{|c|}{$\begin{array}{c}\text { Staphyloccocus } \\
\text { epidermidis }\end{array}$}} & \multirow{2}{*}{\multicolumn{3}{|c|}{$\begin{array}{c}\text { Tricophyton } \\
\text { mentagrophytes }\end{array}$}} & \multirow{2}{*}{\multicolumn{3}{|c|}{$\begin{array}{c}\text { Epidermophyton } \\
\text { sp. }\end{array}$}} & \multirow{2}{*}{\multicolumn{3}{|c|}{$\begin{array}{l}\text { Cândida } \\
\text { albicans }\end{array}$}} \\
\hline & \multicolumn{3}{|c|}{ aureus } & & & & & & & & & & & & \\
\hline & \multicolumn{15}{|c|}{$\%$ of microbial growth reduction after washing cycles ( $\% \pm$ SD). } \\
\hline & 5 & 10 & 15 & 5 & 10 & 15 & 5 & 10 & 15 & 5 & 10 & 15 & 5 & 10 & 15 \\
\hline Trevira $^{\circledR}$ & $79.5 \pm$ & $67.5 \pm$ & $53.5 \pm$ & $85.6 \pm$ & $76.3 \pm$ & $64.2 \pm$ & $82.9 \pm$ & $79.4 \pm$ & $71.1 \pm$ & $86.4 \pm$ & $82.3 \pm$ & $75.6 \pm$ & $74.2 \pm$ & $73.1 \pm$ & $70.8 \pm$ \\
\hline polyester & 4.0 & 3.4 & 2.7 & 4.3 & 3.8 & 3.2 & 4.1 & 4.0 & 3.6 & 4.3 & 4.1 & 3.8 & 3.7 & 3.7 & 3.5 \\
\hline Seacell $^{\circledR}$ & $98.3 \pm$ & $92.4 \pm$ & $84.7 \pm$ & $98.0 \pm$ & $96.3 \pm$ & $90.2 \pm$ & $93.2 \pm$ & $89.1 \pm$ & $80.4 \pm$ & $91.3 \pm$ & $89.1 \pm$ & $85.2 \pm$ & $99.6 \pm$ & $96.2 \pm$ & $90.1 \pm$ \\
\hline viscose & 4.9 & 4.6 & 4.2 & 4.9 & 4.8 & 4.5 & 4.7 & 4.5 & 4.0 & 4.6 & 4.5 & 4.3 & 5.0 & 4.8 & 4.5 \\
\hline
\end{tabular}




\section{Conclusions}

Since the characteristic of the knitted fabrics used in this study are very similar in terms of yarn linear density, course density and wale density, thickness and loop length, the differences observed during the characterization study were mainly attributed to the fabric areal mass, fibre morphology and imbibed materials and not to the fabric structure. All the polyester fabrics in this study have similar thermal conductivity with the exception of the Holofiber ${ }^{\circledR}$ yarn probably due to the higher areal mass of this fabric. The knitted fabrics made with Airclo $^{\circledR}$ and Finecool ${ }^{\circledR}$ yarns display the highest values of thermal resistance and diffusivity and the lowest thermal absorptivity and heat flow because of higher amount of air in the fabric structure that slow the heat transfer process. Conversely, viscose Seacell ${ }^{\circledR}$ displays the lowest thermal resistance and diffusivity and the highest thermal absorptivity and heat flow mainly due to the presence of seaweed and silver in the fibre structure and to the higher density of its structure providing the coolest feeling at the beginning of skin contact. The air permeability of the fabrics seems to depend on the fibre morphology and on the areal mass facilitating the passage of air through the fabric. On one hand, fabrics made from looser and finer yarns such as Finecool ${ }^{\circledR}$ polyester show higher air permeability than dense polyesters such as the control, Coolmax $^{\circledR}$ and Holofiber $^{\circledast}$. On the other hand, the higher water vapour permeability of Finecool ${ }^{\circledR}$ and Trevira ${ }^{\circledR}$ fabrics can be attributed to the lower values of areal mass and with the presence of silver nanoparticle, respectively. $\mathrm{Coolmax}^{\circledR}, \mathrm{Holofiber}^{\circledR}$ and Airclo ${ }^{\circledR}$ fabrics structures with higher densities and peculiar cross-sectional shapes showed low indexes of water vapour transmission rate, however, not so low as for the conventional polyester. In terms of friction Finecool ${ }^{\circledR}$ fibre due to its rhomboid cross section has the highest coefficient of kinetic friction and the Holofiber ${ }^{\circledR}$ fabric the lowest one. In both the horizontal and vertical wicking ability the fabric Coolmax ${ }^{\circledR}$ is higher than that of the others, and the wicking height of the fabric Holofiber ${ }^{\circledR}$ is the lowest. Moreover, despite Finecoo ${ }^{\circledR}$ was designed for optimized moisture management, It showed dramatic lower performance compared to Coolmax ${ }^{\circledR}$ in both vertical and horizontal wicking tests.

Similar trend was observed for the drying capability of the fabrics where Holofiber ${ }^{\circledR}$ shows the higher remaining water ratio. In term of the antimicrobial activity all the microorganisms after 15 washing cycles display an average loss of $10 \%$ in their antimicrobial activity having Seacell ${ }^{\circledast}$ fabrics higher values than Trevira ${ }^{\circledR}$. Technical textiles for sportswear is a very challenging field in which the required functionality can be designed by a suitable choice of raw material, structure and geometry of fibres, yarns and fabrics. According to the results, it can be stated 
that, in term of moisture management only Coolmax ${ }^{\circledR}$ yarns achieve acceptable performance as sportswear fabric in accordance to the minimum quality values of the AATCC 197 and 198 test methods for knit fabrics. Airclo ${ }^{\circledR}$ and Seacell ${ }^{\circledR}$ display the best performances in term of thermal control and antimicrobial properties, respectively.

\section{Author Contributions}

The manuscript was written through contributions of all authors. All authors have given approval to the final version of the manuscript.

\section{Notes}

The authors declare no competing financial interest.

\section{References}

1. Yoo S. Comfort Properties of Heat-Resistant Protective Workwear in Varying Conditions of Physical Activity and Environment. Part I: Thermophysical and Sensorial Properties of Fabrics. Textile Research Journal. 2005; 75: 523-30.

2. Uttam D. Active sportswear fabrics. International Journal of IT, Engineering and Applied Sciences Research. 2013; 2: 34-40.

3. Ciukas R, Abramaviciute J and Kerpauskas P. Investigation of the Thermal Properties of Socks Knitted from Yarns with Peculiar Properties. Part II: Thermal Resistance of Socks Knitted from Natural and Stretch Yarns. Fibres \& Textiles in Eastern Europe. 2011; 19: 64-8.

4. Oglakcioglu N, Cay A, Marmarali A and Mert E. Characteristics of Knitted Structures Produced By Engineered Polyester Yarns and Their Blends in Terms of Thermal Comfort. Journal of Engineered Fibers and Fabrics. 2015; 10: 32-41.

5. Hofer D. Antimicrobial textiles - evaluation of their effectiveness and safety. Curr Probl Dermatol. 2006; 33: 42-50.

6. Vouyiouka SN, Pavlidou S and Papaspyrides CD. Development of advanced textile materials: natural fibre composites, anti-microbial, and flame-retardant fabrics. Proceedings of the Institution of Mechanical Engineers, Part L: Journal of Materials: Design and Applications. 2009; 223: 91-102.

7. Gao Y and Cranston R. Recent advances in antimicrobial treatments of textiles. Textile Research Journal. 2008; 78: 60-72.

8. Allmyr M, Adolfsson-Erici M, McLachlan MS and Sandborgh-Englund G. Triclosan in plasma and milk from Swedish nursing mothers and their exposure via personal care products. Science of the Total Environment. 2006; 372: 87-93.

9. Kanakaraj P and Ramachandran R. Selective Utility Characteristics of Knitted fabrics for Sports Application. Journal of textile and apparel, technology and management 2015; 9: 1-11.

10. Troynikov $\mathrm{O}$ and Wardiningsih W. Moisture management properties of wool/ polyester and wool/bamboo knitted fabrics for the sportswear base layer. Textile Research Journal. 2011; 81: 621-31.

11. Varshney RK, Kothari VK and Dhamija S. A study on thermophysiological comfort properties of fabrics in relation to constituent fibre fineness and cross-sectional shapes. Journal of the Textile Institute. 2010; 101: 495-505.

12. Zhang Y, Wang HP and Chen YH. Capillary effect of hydrophobic polyester fiber bundles with noncircular cross section. Journal of Applied Polymer Science. 2006; 102: 1405-12. 
13. Leonard DR, Farooqi MH and Myers S. Restoration of sensation, reduced pain, and improved balance in subjects with diabetic peripheral neuropathy. Diabetes Care. 2004; 27 : 168-72.

14. Meng Q, Liu J, Shen L, Hu Y and Han J. A smart hollow filament with thermal sensitive internal diameter. Journal of Applied Polymer Science. 2009; 113: 2440-9.

15. Yuan $G$ and Cranston R. Recent Advances in Antimicrobial Treatments of Textiles. Textile Research Journal. 2008; 78: 60-72.

16. Zikeli S. Production Process of a New Cellulosic Fiber with Antimicrobial Properties. 2006; 33: 110-26.

17. Hipler U-C, Elsner $P$ and Fluhr JW. Antifungal and antibacterial properties of a silverloaded cellulosic fiber. Journal of Biomedical Materials Research Part B: Applied Biomaterials. 2006; 77B: 156-63.

18. Oglakcioglu $\mathrm{N}$ and Marmarali A. Thermal comfort properties of some knitted structures. Fibres \& Textiles in Eastern Europe. 2007; 15: 94-6.

19. Havenith G. Interaction of Clothing and Thermoregulation. Exogenous Dermatology. 2002; 1: 221-30.

20. Basal G and llgaz S. A Functional Fabric for Pressure Ulcer Prevention. Textile Research Journal. 2009; 79: 1415-26.

21. Onofrei E, Rocha AM and Catarino A. The Influence of Knitted Fabrics' Structure on the Thermal and Moisture Management Properties. Journal of Engineered Fibers and Fabrics. 2011; 6: 10-22.

22. Kanakaraj P and Ramachandran R. Active Knit Fabrics-Functional Needs of Sportswear Application. Journal of Textile \& Apparel Technology \& Management (JTATM). 2015; 9: 1-11.

23. Zhang J, Rajkhowa R, Li JL, Liu XY and Wang XG. Silkworm cocoon as natural material and structure for thermal insulation. Materials \& Design. 2013; 49: 842-9.

24. Bergmann Tiest WM and Kappers AML. Tactile perception of thermal diffusivity. Attention, Perception, \& Psychophysics. 2010; 71: 481-9.

25. Özdil N, Marmaralı A and Kretzschmar SD. Effect of yarn properties on thermal comfort of knitted fabrics. International Journal of Thermal Sciences. 2007; 46: 1318-22.

26. Mandal S, Song G, Ackerman M, Paskaluk S and Gholamreza F. Characterization of textile fabrics under various thermal exposures. Textile Research Journal. 2012; 83: 1005-19.

27. Gunesoglu S. Heat and mass transfer properties of 2-yarn fleece knitted fabrics. INDIAN JOURNAL OF FIBRE AND TEXTILE RESEARCH. 2006; 31: 415.

28. Hassan M, Qashqary K, Hassan HA, Shady E and Alansary M. Influence of Sportswear Fabric Properties on the Health and Performance of Athletes. Fibres \& Textiles in Eastern Europe. 2012; $\mathrm{Nr} 4$ (93): 82-8.

29. Gunesoglu $S$ and Meric B. Heat and mass transfer properties of 2-yarn fleece knitted fabrics. Indian Journal of Fibre \& Textile Research. 2006; 31: 415-21.

30. Čiukas R and Kerpauskas P. Investigation of the thermal properties of socks knitted from yarns with peculiar properties. Part II: Thermal resistance of socks knitted from natural and stretch yarns. Fibres \& Textiles in Eastern Europe. 2011; 19: 86.

31. Prakash C, Ramakrishnan $\mathrm{G}$ and Koushik CV. A study of the thermal properties of single jersey fabrics of cotton, bamboo and cotton/bamboo blended-yarn vis-a-vis bamboo fibre presence and yarn count. Journal of Thermal Analysis and Calorimetry. 2011; 110: 1173-7.

32. Čiukas R and Abramavičiūte J. Investigation of the Air Permeability of Socks Knitted from Yarns with Peculiar Properties. Fibres \& Textiles in Eastern Europe. 2010; 18: 78.

33. Ramkumar SS, Purushothaman A, Hake KD and McAlister DD. Relationship Between Cotton Varieties and Moisture Vapor Transport of Knitted Fabrics. Journal of Engineered Fibers and Fabrics. 2007; 2: 10-8.

34. BivainytĖ $A$ and MikuČlonienĖ D. Influence of Shrinkage on Air and Water Vapour Permeability of Double-Layered Weft Knitted Fabrics. Materials Science. 2012; 18. 
35. Das B, Das A, Kothari VK, Fanguiero $R$ and de Araújo M. MOISTURE TRANSMISSION THROUGH TEXTILES Part I: Processes involved in moisture transmission and the factors at play. AUTEX Research Journal. 2007; 7: 100-10.

36. Ogulata RT and Mavruz S. Investigation of Porosity and Air Permeability Values of Plain Knitted Fabrics. Fibres \& Textiles in Eastern Europe. 2010; 18: 71-5.

37. Wilbik-Halgas B, Danych R, Wiecek B and Kowalski K. Air and water vapour permeability in double-layered knitted fabrics with different raw materials. Fibres \& Textiles in Eastern Europe. 2006; 14: 77-80.

38. Wang $F$, del Ferraro $S$, Lin L-Y, et al. Localised boundary air layer and clothing evaporative resistances for individual body segments. Ergonomics. 2012; 55: 799-812.

39. Prakash C, Ramakrishnan G and Koushik CV. A study of the thermal properties of bamboo knitted fabrics. Journal of Thermal Analysis and Calorimetry. 2012; 111: 101-5.

40. Wollina $U$, Abdel-Naser MB and Verma S. Skin physiology and textiles - consideration of basic interactions. Curr Probl Dermatol. 2006; 33: 1-16.

41. Akgun M. The Effect of Fabric Balance and Fabric Cover on Surface Roughness of Polyester Fabrics. Fibers and Polymers. 2013; 14: 1372-7.

42. Akgun M. Effect of yarn filament fineness on the surface roughness of polyester woven fabrics. Journal of Engineered Fibers and Fabrics. 2015; 10: 121-8.

43. Manshahia $M$ and Das A. High active sportswear-A critical review. Indian Journal of Fibre \& Textile Research (IJFTR). 2014; 39: 441-9.

44. Yanilmaz $M$ and Kalaoglu F. Investigation of wicking, wetting and drying properties of acrylic knitted fabrics. Textile Research Journal. 2012; 82: 820-31.

45. Bivainytè $A$ and Mikučionienè D. Investigation on the air and water vapour permeability of double-layered weft knitted fabrics. PES. 2011; 8: 29.

46. Fangueiro R, Filgueiras A, Soutinho $F$ and Xie M. Wicking Behavior and Drying Capability of Functional Knitted Fabrics. Textile Research Journal. 2010; 80: 1522-30.

47. Hes $L$ and Carvalho $M$. Diagnostic of the composition of fabrics from their thermal permeability in wet state. INDIAN JOURNAL OF FIBRE AND TEXTILE RESEARCH. 1994; 19: 147-.

48. $\quad$ Schurer NY and Dickel H. Protection from physical noxae. Curr Probl Dermatol. 2007; 34: 98-110.

49. Fluhr JW, Breternitz M, Kowatzki D, et al. Silver-loaded seaweed-based cellulosic fiber improves epidermal skin physiology in atopic dermatitis: safety assessment, mode of action and controlled, randomized single-blinded exploratory in vivo study. Experimental Dermatology. 2009; 19: e9-e15. 